
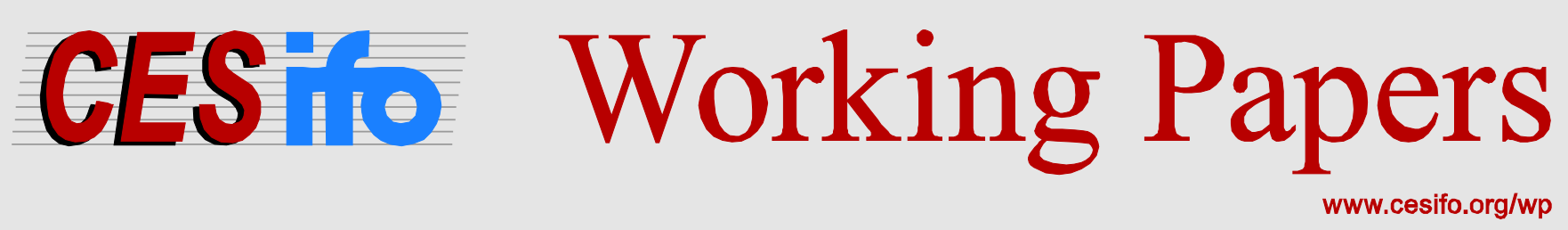

\title{
When Carry Goes Bad: The Magnitude, Causes, and Duration of Currency Carry Unwinds
}

\author{
Michael Melvin \\ Duncan Shand
}

\author{
CESIFO WORKING PAPER NO. 6210 \\ Category 7: Monetary Policy And InTERnAtional FinAnCE \\ NOVEMBER 2016
}

An electronic version of the paper may be downloaded

- from the SSRN website:

- from the RePEc website:

- from the CESifo website:

WwW.SSRN.com

www.RePEc.org

www.CESifo-group.org/wp

ISSN 2364-1428

\section{CESifo}




\title{
When Carry Goes Bad: The Magnitude, Causes, and Duration of Currency Carry Unwinds
}

\begin{abstract}
We analyze the worst currency carry loss episodes in recent decades, including causes, attribution by currency, timing, and the duration of carry drawdowns. To explore the determinants of the length of carry losses, a model of carry drawdown duration is estimated. We find evidence that drawdown duration varies systematically with expected return from the carry trade at the onset of the drawdown, financial stress indicators and the magnitude of deviations from a fundamental value portfolio of the carry-related portfolio holdings. In an out-of-sample test, we show that these determinants can be used to control carry-related losses and improve investment performance.
\end{abstract}

JEL-Codes: E440, F310, G150.

Keywords: carry trade, financial risk, duration, active portfolio management.

Michael Melvin

Rady School of Management

University of California, San Diego

La Jolla / CA / USA

mmelvin@ucsd.edu
Duncan Shand

Warwick Business School

The University of Warwick

United Kingdom - Coventry CV4 7AL

duncan.shand@blackrock.com 
A carry trade is a speculative strategy of buying currencies of countries with high interest rates funded with the sale of currencies of countries with low interest rates. The focus of the literature has been on why such trades should produce positive returns. In international finance classes, students learn that interest rate parity has exchange rates changing to offset the interest differentials on different currencies so that there should be a zero expected profit from carry trades. ${ }^{1}$ While market inefficiency or investor irrationality is a possible explanation for positive carry trade returns, recent research on the topic has pointed to carry trade returns representing a risk premium. ${ }^{2}$

We want to focus on the downside of currency carry trades. While it is well known that the return distribution of such trades has significant negative skewness, the detailed experience of carry drawdowns is less well-known. We seek to fill this hole by cataloging the major carry losses in recent times and identifying the likely factors contributing to each. A major motivation for this work is the development of a duration analysis that will help portfolio managers decide whether to exit their positions once a carry drawdown is realized. This is a dimension of carry trades that is of interest to investors (and their risk managers) that has not been studied in the literature before. It is important to understand in order to assess whether to cut positions once the drawdown has begun, believing that it will persist for some time, or to hold current positions, in the belief that the drawdown will soon reverse and the investor will cut exposures only to

\footnotetext{
${ }^{1}$ Uncovered interest rate parity assumes risk-neutral investors, so it may receive more attention than warranted in a real-world of risk-averse investors.

${ }^{2}$ Studies note the negative skew associated with carry returns. A recent small sample of such papers includes; Daniel, Hodrick, and Lu (2014); Jurek (forthcoming); and Lustig, Roussanov, and Verdelhan (2011).
} 
miss the rebound in asset prices. While every event is different, it is useful to learn what systematic effects may be uncovered by exploring a duration analysis. We introduce 3 variables hypothesized to be related to the duration of carry drawdowns. Market observors know that carry trades perform poorly in times of market stress, so we use a Financial Stress Index (FSI) to measure the time-varying financial conditions. The second variable we investigate is a 'carry opportunity' variable, measured by the average of the interest rates of the long currencies in the portfolio minus the average of the interest rates on the short side of the carry portfolio. The third duration determinant is a measure of spot exchange rate valuation. We find that these variables are significant determinants of carry drawdown duration and show how they can be employed to condition carry trade positioning to reduce losses associated with carry sell-offs.

\section{Returns to Forward Currency Speculation}

We begin by defining $s$ and $f$ as the logs of the spot and forward exchange rates. We measure all exchange rates in units of foreign currency per U.S. dollar. Daily returns from forward speculation are constructed from a strategy of entering into a one-month forward contract at each month end, where the contract is closed out via a spot market transaction at the next month end. This is a carry trade strategy with monthly rebalancing. Log excess returns from a carry strategy may be constructed as the deviation between the initial interest differential and the realized change in the spot rate, or:

$$
r_{t+1}^{i}=i_{t}^{i}-i_{t}^{u}-\left(s_{t+1}^{i}-s_{t}^{i}\right)
$$

where $i_{t}^{u}$ denotes the US interest rate. Covered interest parity ensures that the forward discount/premium is equal to the interest differential, or approximated by 


$$
f_{t}^{i}-s_{t}^{i} \approx i_{t}^{i}-i_{t}^{u}
$$

Substituting equation (2) into equation (1), one sees the familiar returns to forward speculation construction

$$
r_{t+1}^{i}=f_{t}^{i}-s_{t+1}^{i}
$$

Currency investors are "marked-to-market" daily in order to compute the daily returns to the portfolio. Even though the existing forward positions are held through time and not closed out each day, daily returns to the positions are calculated using current spot exchange rates and forward points to infer a "current" forward rate which is interpolated to the settlement date of the existing forward contract. This determines an appropriate level of the "current" forward rate to compare with the existing forward rate in order to compute gain or loss if one closed out the position today. We use monthly interest rates each day in order to calculate the forward points used in computing the daily returns. Where portfolio drawdown returns are calculated, we use excess returns rather than log excess returns.

Data. The basic data are spot and one-month forward exchange rates and are taken as the WMR rates sampled at 4pm in London on Datastream. We focus on the following set of currencies that are widely traded by active currency investors. The developed market (DM) portfolio consists of ${ }^{3}$ Australia (AUD), Canada (CAD), euro (EUR), Japan (JPY), New Zealand (NZD), Norway (NOK), Sweden (SEK), Switzerland $(\mathrm{CHF})$ and the United Kingdom (GBP). ${ }^{4}$ The emerging market (EM) universe consists of

\footnotetext{
3 The three letter codes used here are as defined in ISO 4217.

${ }^{4}$ Prior to the launch of the EUR in 1999, the legacy national currencies were used in determining carry portfolios. While all of these currencies are available for selection, currencies that show up in portfolios
} 
Brazil (BRL), Chile (CLP), Colombia (COP), Czech Republic (CZK), Hungary (HUF), India (INR), Indonesia (IDR), Malaysia (MYR), Mexico (MXN), Peru (PEN), Philippines (PHP), Poland (PLN), Romania (RON), Russia (RUB), Singapore (SGD), South Africa (ZAR), South Korea (KRW), Taiwan (TWD), Thailand (THB) and Turkey (TRY). The DM data sample covers the period of December 1983 - August 2013 and the EM sample is the period February 1997 - August $2013 .{ }^{5}$ The analysis below will consider carry returns of the full sample of currencies (All) as well as the performance of portfolios of just DM or just EM.

Portfolio Construction. Portfolios are constructed by ordering all currencies in the investment universe based upon interest rates. At each time $t$ currencies are ranked from high to low based upon interest differentials versus the US dollar. Grouping currencies into portfolios is arbitrary and one can create portfolios by grouping all currencies into high to low portfolios or just trading the top three versus the bottom three, or any other arbitrary grouping scheme. In all cases, the strategy is to take long positions in the high interest rate currencies and fund these with short positions in the low interest rate currencies. ${ }^{6}$

below (see Table 2) include Belgium (BEF), Finland (FNM), France (FRF), Germany (DEM), Ireland (IEP), Italy (ITL), and Netherlands (NLG).

${ }^{5}$ The shorter EM sample reflects the presence of fixed exchange rates and illiquidity that existed historically. We begin the sample when liquidity and volatility present adequate EM investment opportunities for currency investors.

${ }^{6}$ Quantitative fund managers will often construct carry portfolios using mean-variance optimization so that return correlations across currencies will help determine the portfolio holdings. However, our construction uses only levels of interest differentials. Some investors may also volatility scale the interest rates to incorporate another measure of risk. 
Recently, some researchers have used a portfolio construction approach assigning currencies to hierarchical portfolios based upon interest rates (for instance, Lustig, Roussanov, and Verdelhan (2011)), in a so-called HML (high minus low) portfolio construction strategy. Currencies are ranked from high to low interest rates and then the currencies are assigned to six different portfolios, starting with the lowest rate currencies being assigned to portfolio 1 , next higher to portfolio 2 , and so on until each portfolio has an equal number of currencies. Then any remainder of high-yielding currencies is assigned to the highest portfolio. The investor then takes long positions in the currencies in the highest interest rate portfolio and short positions in the lowest interest rate portfolio currencies. This is reasonable for analysis or investing with a large number of assets. However, if one has a low-breadth strategy, as exists in currencies, then it may be more reasonable to approach the issue more directly by simply going long the top 3 currencies versus shorts in the bottom 3 , equally weighting all. This approach would be more representative of the carry trades actually implemented in the market, in particular a DM carry portfolio with only 9 investible assets does not lend itself to the HML construction ${ }^{7}$. The carry trade is quite similar when both portfolio construction methodologies are compared. As a result, we will focus on the simpler methodology in the remainder of the paper.

Backtest Experience. For DM currencies, we construct returns to the carry trade portfolio over the period of December 1983 to August 2013. For EM currencies, the

\footnotetext{
${ }^{7}$ Note that DM carry strategies have been available to retail investors through ETFs. The Deutsche Bank Currency Harvest Index is representative of a tradable index using the top-3, bottom-3 construction described here (Bloomberg code DBHVG10U).
} 
sample is much shorter, starting in February 1997, and reflects lack of flexible exchange rates and illiquidity that exists historically. We construct a portfolio of all EM and DM currencies by adding the EM currencies to the DM portfolio as they come on-line in the sample. The first set of results includes all currencies and then the results are recomputed over just the developed market sample and, finally, over just the shorter emerging market sample. Figure 1 plots the returns to the carry trade since 1983 for the full sample of DM and EM currencies ${ }^{8}$ using the simple strategy of taking long positions in the three highest interest rate currencies funded by short positions in the three lowest interest rate currencies. Overall, one can see that the carry trade was a good performer, with only a few significant setbacks until the time of the financial crisis when the drawdowns became larger and more frequent. We will present a review of the largest drawdowns in a later section, but one can now see that the drawdowns have been quite heterogeneous in terms of duration and magnitude.

Figure 2 presents the cumulative returns to a top-3/bottom-3 portfolio approach for the DM and EM currencies. A comparison of DM carry returns, in Figure 2.a, with EM carry returns, in Figure 2.b, illustrates some interesting differences. Overall, EM carry returns have outperformed DM returns in the period of overlap. In addition, the financial crisis is seen as a DM-oriented event, where there was a severe drawdown for the DM currencies but the EM currencies came through it with only a small drawdown in comparison. One can see the importance of the choice of currency universe as the returns to carry may differ substantially. Over the period since 1997, when the EM return series

\footnotetext{
${ }^{8}$ As mentioned above, the early sample period contains only DM currencies but as data are available for the EM currencies they are added over time.
} 
begins, the correlation between DM and EM carry returns has been just 0.26 . One commonality is that carry performance has been challenging for both DM and EM since the financial crisis. The interest rate convergence that has occurred in that time is certainly one factor that may have temporarily reduced the opportunity set for carry trades.

\section{Top Carry Crashes}

While carry trades have offered positive returns over the long-run, it is well known that they are subject to tail risk of large drawdowns. Figure 3 provides histograms and summary statistics for daily carry portfolio returns over the period of overlap between the DM and EM portfolios. The DM returns distribution has a mean of 0.02 percent, or 2 basis points, and a skew of -0.95 , while the EM distribution has a mean of 0.06 percent, or 6 basis points, and a skew of -2.15. Pooling both DM and EM currencies into the "All" currency portfolio over the common EM and DM sample period of, yields a mean return of 0.04 percent, or 4 basis points, with a skew of -1.70 . The summary statistics and histograms reflect the known tail risks associated with currency carry trades.

Digging deeper into the left tail of carry returns, in this section we examine the worst drawdowns in recent experience. Drawdowns are calculated using the following methodology: a peak is determined as the highest point up until time $t$ in the cumulative return series. A trough is the lowest point following a peak before a new peak is established. The magnitude of the drawdown is the cumulative fall from peak to trough. 
The duration of the event is measured by the number of days from peak to trough. More formally, if $X=(X(t), t \geq 0)$ is a sequence of cumulated returns (with $X(0)=1)$ then the drawdown at time $t$ (denoted $D D(t))$ is defined as:

$$
D D(t)=\max \left\{0, \max _{t \in(0, T)} X(t) / X(T)-1\right\}
$$

For a backtested investment strategy, we can calculate a drawdown for each time period, and sort and rank the drawdowns. This definition would give a non-zero drawdown for any period in which a negative return was experienced, in practice this is not valuable and we set a somewhat arbitrary cut-off in terms of the size of drawdown. We calculate the top-10 drawdowns for the three different portfolios: developed markets, emerging markets, and the combined portfolio of all currencies. To ensure comparability of the returns, each portfolio is scaled to achieve an ex-post risk level of 10 percent over the sample period. ${ }^{9}$

Table 1 lists the top 10 drawdowns for the different portfolios of currencies. For each episode, the table lists the magnitude, length, and beginning and ending dates of the drawdowns. DM currencies, in Table 1.a., experienced top-10 drawdowns ranging from 31.99 percent and 399 days to 7.15 percent and 30 days. The worst drawdown began in late-July 2007 and ended in early February 2009. The summer of 2007 was the first wave of the sub-prime crisis in the U.S and also the period of the quantitative equity crisis (Khandani and Lo, 2007). Negative impacts were seen first in fixed income

\footnotetext{
${ }^{9}$ Assuming we have $n$ carry strategy returns $\mathrm{x} 1, \ldots, \mathrm{xn}$, to scale the carry returns to $10 \%$ ex-post volatility we simply scale by $0.1 /(\operatorname{std}(\mathrm{x} 1, \ldots, \mathrm{xn}) * \operatorname{sqrt}(\operatorname{annFac}))$ where annFac for the daily returns is 260 , i.e. we simply divide by the annualised ex-post volatility and multiply by 0.1 . This is done to be able to give an apples-to-apples comparison of the portfolios for the 3 universes and is not intended to show any in-sample risk management. Note that this is done for comparing returns on an equal risk footing and does not affect the portfolio construction as addressed in footnote 6 earlier.
} 
returns, and then equity returns, and, finally, currency returns beginning in late-July. The magnitude and duration of the carry unwind associated with the financial crisis was quite unlike any other DM currency event since the early 1990s. Section 1.b. in Table 1, shows that the worst drawdown of 16.90 percent for EM currencies began mid-February 1998 and lasted 92 days, until mid-June. This drawdown was associated with Indonesia and the lingering effects of the Asian financial crisis. It is interesting to note that the global financial crisis is associated with the second worst drawdown for EM markets, of 16.38 percent and 36 days. A brief narrative on each of the top-10 drawdowns for DM and EM currencies is provided in the Appendix.

Finally, Section 1.c. of Table 1 lists the top-10 drawdowns for the combined portfolio of DM and EM currencies. The top drawdown of 23.08 percent overlaps with the period of the financial crisis. The second-worst drawdown overlaps with the secondworst DM drawdown and incorporates the period of the European Exchange Rate Mechanism (ERM) crisis. The sensitivity of the results to choice of currency universe is clear. We calculate an "agreement" index to identify the frequency with which one currency universe is experiencing a top-10 drawdown when the other universes are not. Doing so, we see that on 41 percent of the days which are identified as drawdown periods for either EM or DM universe, the EM and DM portfolios do not experience drawdowns at the same time

To better understand the experience of carry drawdowns, a decomposition of each of the top carry crashes was done by currency (all returns are measured versus the US 
Dollar). This allows a view into which currencies contributed most to the negative performance. ${ }^{10}$ Table 2 lists the currencies in each of the top-10 negative return portfolios and their contribution to the carry drawdown. For each episode, Table 2 reports the magnitude, beginning date and individual currency information in terms of contribution to the overall carry strategy return (what this currency's return adds or subtracts to the overall portfolio), exchange rate return versus the U.S. dollar (return to the forward position in the currency), and mean holding over the drawdown period. While the top-3, bottom-3 strategy will have each currency in the portfolio with a +1 or 1 holding, depending upon whether the portfolio holds a long or short position, over the duration of a carry drawdown the ranking of currencies may change each month so that some currencies enter the carry portfolio while others drop out, so that there may be more than 6 currencies held in each drawdown period. In addition, it is possible to have a mean zero holding when the strategy switches between a short and long position over the sample period.

Since the carry trade is long high-interest rate currencies and short low-interest rate currencies, and a carry crash occurs in a de-risking or de-leveraging event, we should expect the (formerly) high-interest rate currencies to be sold and the (formerly) lowinterest rate currencies to be bought as investors close out or reduce their carry positions. Over the sample period studied, that generally means that positions in relatively highinterest rate currencies like the Australian and New Zealand dollar are sold to close out

\footnotetext{
${ }^{10}$ While our portfolio construction method ranks currencies by interest rates and trades the top and bottom 3 in a long-short portfolio, we are not suggesting a passive approach to currency carry trades. Such trades should be actively managed to control the tail risk described above. We will illustrate an active management risk control in the following sections after we have presented a model of drawdown duration.
} 
long positions, while relatively low-interest rate currencies like Japanese yen and Swiss franc are bought to close out short positions. Table 2.a. indicates that these classic carry trade currencies are typically at the top of the list of contributors to the DM carry drawdowns. The second-largest DM drawdown beginning September 1992 was different in that it was the longest duration and involved quite a mix of currencies. Early in that episode, the European exchange rate mechanism or ERM crisis emerged with the withdrawal of Italy and the UK from the exchange rate mechanism. We see the Italian lira figuring prominently in the negative returns but the pound recovered its value over the long period of the drawdown. Only three of the top-ten DM drawdowns had the minimum six currency portfolio. In all other cases, currencies would exit and be replaced by another. For instance, the third-largest drawdown beginning April 1986 held a long Norway position for about 85 percent of the period, with the NOK being replaced by the Italian lira for about 15 percent of the time.

Emerging market currencies are not as well-studied as DM currencies, so the results reported in Table 2.b. may be even more instructive. Of course, the same general dynamic should be observed where (formerly) high interest rate currencies are sold while low interest rate currencies are bought as investors reduce or close out their carry positions as part of a de-risking or de-leveraging event, leading to negative returns for those holding carry portfolios. However we do see a different dynamic in the EM portfolio, with most EM currencies depreciating against the US dollar over drawdown periods. For example, the second-largest EM drawdown occurred in the period around the Lehman crisis. We see one of the worst performing currencies over the period was the 
Korean Won (depreciating against the USD by about 19\% over the drawdown period), which was actually short in the carry portfolio, so delivered a positive contribution to the portfolio. Other short carry currencies tended to depreciate less, e.g. the Malaysian ringgit depreciated by $3.7 \%$ and the Singapore Dollar by $4.9 \%$. However, the big losses in the portfolio came on the long side as the long carry currencies of Brazilian real (which depreciated by 34\%), Turkish lira (30\%), and South African Rand (35\%) generated large losses for the carry portfolio.

This evidence suggests that investors have sold both high and low interest rate currencies during EM carry crashes. Given the correlation of risk premia at times of high financial market stress, it may be that the EM currencies are being sold for reasons other than pure foreign exchange carry purposes. In many cases, there is a general exit from EM financial assets in a risk-off event that sees all EM assets sold (stocks, bonds, and currencies). Some names repeat across carry crashes and are found at the top of the attribution list for EM currencies in Table 2.b. This includes relatively high interest rate currencies like Turkish lira (TRY), Brazilian real (BRL), and South African rand (ZAR) along with relatively low interest rate currencies like Taiwan dollar (TWD), Czech koruna (CZK), and Singapore dollar (SGD).

Combining DM and EM currencies together into one carry portfolio we see that the EM currencies are often at the top of the list of contributors to the carry crashes in Table 2.c. The Japanese yen (JPY) and Swiss franc (CHF) are the most prominent DM currencies in this table, as investors may take short yen and Swiss positions to fund long positions in EM currencies. It is also interesting to note how many currencies are entering and exiting the top-3/bottom-3 carry portfolio. For instance, the top drawdown 
occurring during the financial crisis has only one currency, the JPY, that remains in the portfolio the entire period. A total of 12 currencies appear over the duration of the drawdown, with 9 of the 12 being EM currencies. Only the JPY, CHF, and, briefly, the EUR appear from the DM currencies. One factor related to the number of currencies entering or exiting the portfolios is the duration of the drawdown. The shorter the drawdown period, the more likely the original six currencies in the portfolio will be held throughout the drawdown. Looking across the top-10 drawdowns for the combined EM/DM portfolios, it is not surprising that when DM currencies appear, they tend to be relatively low-interest rate funding currencies where short positions are held. There are a few exceptions to this, like the long AUD, NZD, and NOK in the fourth largest drawdown from the summer of 1986.

\section{Determinants of Carry Drawdowns}

We investigate three variables which we hypothesize are related to the duration of carry drawdowns: financial market stress, the size of the carry opportunity at the start of the drawdown and deviations from fair value of the carry portfolio at the start of the drawdown.

Financial Stress Index. Carry trades underperform during periods of financial market stress. ${ }^{11}$ To analyze the effects of such stress events, we utilize a Financial Stress

\footnotetext{
11 There are several studies that offer supportive evidence, including Melvin and Taylor (2009); Daniel, Hodrick, and Lu (2014); and Jurek (2014).
} 
Index (FSI) created by Melvin and Taylor (2009). This index follows the IMF (2008) in the choice of input variables. ${ }^{12}$ The variables are:

- Bankbeta: Let bank $_{a}$ be a daily bank industry index for a country $a$ and $e q_{a}$ be the daily broad market index. We calculate year on year returns $\operatorname{bankYoY}_{a, t}=\left(\operatorname{bank}_{a, t} / \operatorname{bank}_{a, t-260}\right)-1$ and $e q Y o Y_{a, t}=\left(e q_{a, t} / e q_{a, t-260}\right)-1$, and calculate the beta as the 1 year $\operatorname{rolling} \operatorname{cov}\left(e q Y o Y_{a, t}, \operatorname{bankYoY_{a,t}}\right) / \operatorname{var}\left(e q Y o Y_{a, t}\right)$. When the beta of bank stocks is relatively high, this suggests that banking stocks are moving more than usual with the overall stock market and bank stocks may be considered more risky than in other times.

- TEDspread: Let $i b 3 m_{a, t}$ be the $3 \mathrm{~m}$ interbank rate for country $a$ at time $t$ and $r 3 m_{a, t}$ be the the $3 \mathrm{~m}$ government treasury bill yield. Then the average TEDspread variable over the G10 developed market universe is defined as $\sum_{a \in G 10}\left(i b 3 m_{a, t}-r 3 m_{a, t}\right) / 10$. This measures a risk premium on unsecured lending in the interbank market, which will rise in times of financial market stress.

- Yieldslope: the inverted slope of the yield curve. Let $r 3 m_{a, t}$ be the $3 \mathrm{~m}$ government treasury bill rate and $r 10 y_{a, t}$ be the 10 year treasury bond rate for a country $a$ at time $t$, then the average Yieldslope variable is defined as $\sum_{a \in G 10}\left(r 3 m_{a, t}-r 10 y_{a, t}\right) / 10$. A flattening of the yield curve will affect the health of the banking industry in that it affects the profitability of financial intermediation.

\footnotetext{
${ }^{12}$ Melvin and Taylor (2009) used the IMF variables to create a tradable version of the FSI and we replicate that here.
} 
In addition, the slope of the yield curve also serves as a leading indicator of economic growth where an inversion is often associated with a growth downturn.

- EquityReturn: For the daily broad equity market index $e q_{a}$ for country $a$, we calculate the average monthly equity return over the G10 universe as:

$\sum_{a \in G 10}\left(e q_{a, t} / e q_{a, t-20}-1\right) / 10$. Financial stress events are associated with a drop in equity prices.

- EquityVol: Let eqret $_{a, t}$ be a daily equity return for country broad market index $a$ at time $t$. We calculate $e q v o l_{a, t}$ as the 780 day half-life exponentially weighted moving standard deviation of eqret $_{a, t}$, and average across the G10 equity market indexes. In times of stress an increase in equity market volatility signals greater risk and uncertainty.

- Currencyvol: : Let fxret $t_{a, t}$ be a daily spot exchange rate return for country $a$ relative to the US Dollar at time $t$. We calculate $f x v o l_{a, t}$ as the 780 day half-life exponentially weighted moving standard deviation of $f x r e t_{a, t}$, and average across the G10 currencies. Exchange rate volatility reflects greater risk associated with financial markets.

- CorpSpread is the daily BofA Merrill Lynch US Corporate A yield - long term government bond (OAS) Index. Spreads on corporate bonds above government bonds reflect greater default risk of corporates in times of stress.

We construct a Global FSI by equally weighting each of the individual measures. The construction methodology derives global scores for each measure by equally weighting the underlying country scores. The "scores" are standard-normal variables (z-scores) 
using time-varying means and variances of the underlying series constructed using exponentially-weighted moving averages of the mean and standard deviations using 36 month half-lives.

The Global FSI and its components are plotted in Figure 4. One can see that the major market events during the period are reflected in the FSI. The FSI rises abruptly during the early wave of the sub-prime crisis in 2007 and peaks following the Lehman Bros. bankruptcy in 2008. One can also note in Figure 4 how much the different subindices vary through time. Looking at any one of the components could give, at best, a partial view of the risk environment. By looking across the spectrum of risk indices, one has a more reliable view of the risk regime. We will employ these measures to assess the extent to which they can explain the duration of carry trade drawdowns. ${ }^{13}$

Carry Trade Opportunity Set. Since the carry trade involves going long the high interest rate currencies versus shorts in the low interest rate currencies, one would expect the return on the carry trade, and therefore positioning, to be a function of the magnitude of the interest differentials across currencies. The greater the interest differentials between currencies, the greater the opportunity for carry profits, other things equal. We measure the carry opportunity as the simple average of the long minus the short interest rates in the carry portfolio in each period:

\footnotetext{
${ }^{13}$ Any empirical analysis covering the period studied here, 1999-2013, incudes the financial crisis and as seen in Figure 4, the crisis was truly exceptional in terms of realized data. Table 1 shows that the crisis period was the largest drawdown for DM carry and the second-largest for EM carry, but was not the longest duration for either.
} 


$$
C A R R Y=\left\{\sum_{a=1}^{3} i b 3 m_{a, t} / 3 \mid H_{a, t}>0\right\}-\left\{\sum_{a=1}^{3} i b 3 m_{a, t} / 3 \mid H_{a, t}<0\right\},
$$

where $H_{a, t}$ denotes holdings of currency $a$ at time $t$.

Deviations from Fundamental Value. Many active currency managers employ fundamental value strategies, such as deviations from purchasing power parity (PPP), as well as carry strategies, in their portfolios. ${ }^{14}$ When the two strategies are both signaling the same portfolio position, we may expect the overall currency positioning to be larger as the value positions align with the carry positions compared to periods when the strategies disagree on positioning. The value signal is measured by deviations of spot exchange rates from IMF annual purchasing power parities (PPPs) for individual countries, or AssetMisVal $t_{t}\left(P P P_{a, t}-\right.$ spot $\left._{a, t}\right) /$ spot $_{a, t}$. For the euro, the OECD annual purchasing power parity was used. The Misvaluation variable uses the carry portfolio holdings to calculate the average misvaluation for the long currencies minus the short currencies as

$$
\begin{aligned}
\text { Misvaluation } & =\left\{\sum_{a=1}^{3}\left[\left(P_{a, t}-\text { spot }_{a, t}\right) / \text { spot }_{a, t}\right] / 3 \mid H_{a, t}>0\right\} \\
& -\left\{\sum_{a=1}^{3}\left[\left(P P P_{a, t}-\text { spot }_{a, t}\right) / \text { spot }_{a, t}\right] / 3 \mid H_{a, t}<0\right\}
\end{aligned},
$$

where $H_{a, t}$ denotes holdings from the carry portfolio (long highest interest rate currencies and short lowest interest rate currencies). A positive value of Misvaluation means that the carry long currencies are more overvalued than the carry shorts. In this

\footnotetext{
${ }^{14}$ In fact, both carry and PPP are sometimes referred to as "generic" currency strategies due to their longstanding popularity among currency investors (see Melvin and Shand (2011) or Pojarliev and Levich (2008) for further discussion).
} 
case, the long currencies would depreciate to move closer to PPP values so portfolio managers looking for reversion to PPP would take short positions, and this conflicting signal between carry and PPP would work to offset the carry trade positions. In the case where the long carry currencies are undervalued in a PPP sense, the Misvaluation variable takes a negative value so that the valuation signal reinforces the positioning of the carry portfolios. The model of duration developed in the next section will allow us to assess, given values for the FSI and Carry, if the duration of carry drawdowns varies systematically depending upon the sign and magnitude of Misvaluation. ${ }^{15}$

\section{Duration of Carry Drawdowns}

Determinants of carry returns have been studied before, but to our knowledge, we are the first to analyse the duration of carry drawdowns. The duration of carry drawdowns is of great importance to portfolio managers (and risk managers). In real time, once a carry drawdown begins, portfolio managers must decide whether to cut positions in anticipation that the carry sell-off will persist for some time into the future, or hold the current positions in anticipation that a reversal will likely happen soon and the rebound in asset prices will be missed if exposures are reduced. While we have seen that each episode tends to be different, it is of interest to better understand the determinants of the length of carry drawdowns and explore any systematic effects that may exist. In this section, periods of carry drawdown are identified and the duration of drawdowns investigated. It is first necessary to identify the drawdowns themselves as not every

\footnotetext{
${ }^{15}$ An interesting application of deviations from fundamental value related to carry trades is provided by Jorda and Taylor (2012) where they employ a measure of PPP deviations as a conditioning variable.
} 
negative period (i.e. a single negative day for example) would be identified as a drawdown by a fund manager. A somewhat arbitrary cut-off of $1.5 \%^{16}$ is used to identify the drawdowns. ${ }^{17}$ This gives 54 for DM and 49 for EM.

The duration of carry drawdowns varies considerably, from 1 to 689 days for DM, and from 1 to 623 days for EM. It is not obvious why some carry unwind events last so long, while others are so brief. As a result, it is of interest to explore whether duration varies systematically over time and what the determinants of such variation might be. To this end, we estimate models of the duration of DM and EM carry unwinds as a function of the three variables described earlier.

a) Global FSI at the start of the drawdown. The hypothesis is that the greater the stress in financial markets, the longer the duration of the drawdown event.

b) Carry opportunity at the start of the drawdown. The hypothesis is that the greater the interest differentials at the start of the drawdown, the greater carry positioning is likely to be so that there is more incentive to cut positions quickly (don't be last out the door).

This hypothesis may be consistent with the view modelled in some recent papers where carry returns are seen as a risk premium against "crash-risk" - the risk of a significant loss. In this setting, higher expected returns may be systematically associated with higher expected loss if risk sentiment declines.

\footnotetext{
${ }^{16}$ For comparability across portfolios, the portfolios for each of the different universes are scaled to deliver $10 \%$ ex-post risk. We examined robustness to alternative cut-offs like $1 \%$ and $2 \%$ and find that, while the magnitudes of the parameter values change, the qualitative inference is the same. One cannot raise the cutoff above $2 \%$ without reducing the sample size to a point where we would have less confidence in the estimation results.

${ }^{17}$ Clearly a one-day drawdown of $1.5 \%$ is a different event than a 30 -day drawdown of $1.5 \%$, the latter being less shocking and offering more of an opportunity to mitigate the loss with a derisking strategy.
} 
c) Exchange rate misvaluation at the start of the drawdown. As defined in equation (6), a positive number means that the carry long currencies are more overvalued than the carry shorts. In this case, the long currencies would need to depreciate more (or appreciate less) than the short currencies for the valuation gap to shrink. At any point in time, there are value-oriented investors taking positions that may, or may not, align with carry positioning. If the misvalulation variable is positive, then value investors would tend to be short (long) the overvalued (undervalued) carry long (short) currencies in their value trades so that overall currency positioning is moderated by the value positions being opposite the carry positions In this case, a carry sell-off will be aligned with correcting deviations from fundamental value and will reward the value positions. Consistent with the crowded-trades argument of the Carry variable, the more crowded the currency positioning, the faster the exit from the carry trade as no one wants to be "last out the door." So when value and carry positioning have different signs, then only the carry positions need to be reduced in this case, and this may occur more slowly (i.e. the duration is longer) than a carry sell-off where the Misvaluation variable is negative so that the deviation from fundamental value is aligned with the carry positions and overall currency market positioning in line with the carry trade is larger. Now both the carry and the value positions will suffer losses when the carry unwind begins and both will be reduced. In this case, event duration may be expected to last a shorter time due to the fundamental value positioning trades reinforcing the carry trade unwinds and investors hurrying to exit their positions before further losses are imposed by others doing the same. We expect that for any given size of the FSI and carry trade opportunity given by interest differentials, the greater the misvaluation that is aligned with carry positioning, 
the shorter the duration of the drawdown due to position unwinds motivated by both carry and value. ${ }^{18}$

Estimated models of duration allow inference with regard to effects of explanatory variables and also provide information on the shape of the hazard function. A hazard function measures the probability that a duration event lasting until time $t$ ends in the next short interval of time following $t$. An upward (downward)-sloping hazard function is said to have positive (negative) duration dependence, where the likelihood of the event ending right after $t$, conditional upon duration lasting up to $t$ is increasing ( decreasing) in $t$. In our application, the question is whether a carry drawdown is more or less likely to end right after $t$ given that it has lasted until time $t$. In order to allow flexibility in the shape of the estimated hazard function associated with length of carry drawdowns, we specify a hazard model based upon the Weibull distribution. ${ }^{19}$ The Weibull base hazard rate can be written as:

$$
\lambda_{0}(t)=(v / \rho)(t / \rho)^{v-1}
$$

where $\rho$ is a scale parameter and $v$ is a shape parameter. The hazard rate conditioned upon an individual observation $i$ on the explanatory variable $x$ is:

$$
\pi_{i}\left(t \mid x_{i}, \nu, \rho, \beta\right)=\lambda_{0}(t) e^{\beta x_{i}}
$$

\footnotetext{
${ }^{18}$ Investors fleeing perceived crowded trades is a subject studied by Pedersen (2009) and Pojarliev and Levich (2011).

${ }^{19}$ One frequently sees duration models in finance estimated assuming an exponential distribution. While this is simpler to estimate, with a constant hazard rate, there is no reason why the hazard should be a constant and we prefer to let the data speak as to the slope of the hazard function.
} 
where $\beta$ represents parameter estimates. With the three explanatory variables listed above, the Weibull model of carry drawdown duration is estimated via maximumlikelihood..$^{20}$

Estimates of the duration model are presented in Table 3. The regressors do not change the duration dependence, or upward- or downward-shape of the hazard function, which is determined by the value of $v$. Instead, the explanatory variables may be thought of as shifting the units of measurement along the time axis. A positive (negative) shift in the hazard rate translates into an increase (decrease) in the hazard rate and, thus, a higher (lower) probability of a duration event ending after $t$, given that it has lasted until $t$. The results in Table 3 indicate that the hazard rate is decreasing in the FSI variable for the DM and ALL samples and increasing for the EM sample. So for DM events, duration is expected to be longer, the greater the degree of financial crisis, as measured by the FSI. For EM, duration is expected to be shorter the greater the FSI value. The different signs for DM and EM are puzzling, but this may be an artefact of the DM sample starting in 1983 and the EM sample starting in 1997. The DM sample has some of its largest duration events prior to 1997, including its biggest associated with the ERM crisis in Europe. In addition, since the FSI variable was created using DM financial conditions data, maybe it is not surprising that the results differ.

Turning to the other explanatory variables, the results suggest that the hazard rate is increasing in the size of the carry opportunity at the start of the drawdown for the DM

\footnotetext{
${ }^{20}$ The exact estimation method is found in Matlab as the Weibull-Cox model.
} 
and All samples but decreasing in Carry for the EM sample. The interpretation of the former is that the probability of a carry drawdown event ending after time $t$, given that it has lasted until $t$, is higher, the greater the magnitude of the carry trade opportunity existing at the start of the drawdown. It is well known that carry trades are subject to periodic tail events where losses can be severe and this creates a sensitivity to market conditions to react quickly if carry trade losses are observed. So while larger interest differentials between the carry-long and carry-short currencies create greater profit opportunities, ${ }^{21}$ these same interest differentials can also create greater potential loss if one holds positions when others exit. It is not surprising that larger interest differentials result in shorter duration of carry drawdowns as positions tend to be exited via mass selloffs as investors race to be among the first to exit. Once again, we see different results for the EM sample, where the greater the interest differentials at the onset of the drawdown, the longer the duration. As with the FSI interpretation, the fact that the DM sample begins in 1983 while the EM begins in 1997 is most likely the reason different estimation results are found. ${ }^{22}$ A more fundamental reason may be that the lower liquidity and higher trading costs associated with EM currencies does not allow as quick an exit from positions as is possible for the DM currencies. Higher short term interest rates could also signify a move to protect a currency from speculative attack or increased onshore creditrisk in the financial system either of which could prolong the drawdown.

\footnotetext{
${ }^{21}$ We estimated carry return regressions as a function of the Carry variable and confirm that the returns to the carry trade are increasing in the size of interest differentials between the carry-long and carry-short currencies.

22 If we start the DM sample in 1997 to match the starting year of the EM sample, we only have 26 observations, so any evidence must be considered in light of the small number of observations. However, if we do estimate the DM hazard function using those 26 carry drawdowns since 1997, we find negative coefficients for the Carry variable similar to the EM findings.
} 
The size of the misvaluation from PPP of the carry-long currencies minus the carry-short currencies has a negative coefficient as shown in Table 3 for all samples. Since a negative value of the Misvaluation variable signals value positioning that aligns with carry positioning, the greater the undervaluation of the carry-long currencies relative to the carry-short currencies, the lower the value of the Misvaluation term, and the greater the hazard value and shorter the duration of carry drawdowns. For any given level of financial stress and carry opportunity, the greater the misvaluation from PPP that results in expected returns in the same direction as carry returns, the greater the value of the hazard function and the shorter the duration of the drawdown, for all currency universes. The interpretation is similar to that of the Carry variable in that when the value signal positioning aligns with the carry positioning, overall positioning will be more crowded and active investors in both trades will exit once losses are realized and the realization of both types of positions being unwound shortens the duration of losses on similarly positioned carry trades. And, of course, the converse is true. When deviations from PPP result in positioning opposite that of carry positioning, the value trades earn positive returns when carry sells off and overall currency positioning would be smaller so that only the carry trades are exited so that the duration of the carry drawdown is longer. One general takeaway from both the Carry and Misvaluation results is that conditions aligned with more crowded positions generate faster risk reduction and shorter drawdown duration.

To get a sense of the economic significance of the explanatory variables, we simulated the model at the mean of the explanatory variables to obtain a baseline hazard 
rate for 30 days and then shocked each variable by two standard deviations to infer the shift in the hazard rate at 30 days. The baseline 30 day hazard rate is 0.0263 , or there is a $2.63 \%$ chance that a carry drawdown that has lasted 30 days will end on day 31 . If the FSI increases by two standard deviations, given the mean values of the other variables, the hazard falls but slightly to $2.49 \%$. A two standard deviation increase in Carry, raises the hazard rate to $3.71 \%$. Finally, a two standard deviation increase in the Misvaluation variable lowers the hazard rate to $1.17 \%$. In terms of economic significance, shifts in the FSI have less of an effect on the probability of a drawdown ending than shifts in Carry or Misvaluation.

The Weibull model employed allows for a regression-like interpretation of the estimated coefficients as semi-elasticities of the hazard rate with respect to the variables. For instance, the Carry coefficient in the DM estimation of 4.008 suggests that a $1 \%$ increase in the carry return available at the onset of a drawdown is associated with an approximate $4 \%$ increase in the hazard rate and, therefore, a decrease in the expected duration of carry drawdown.

The shape $(\rho)$ and scale $(v)$ parameters estimated for the DM and EM models result in a hazard function shape as displayed in Figure 5. All three hazard functions have negative duration dependence, where the likelihood of a drawdown ending right after $t$, conditional upon duration lasting up to $t$ is decreasing in $t .^{23}$ In the case of the

\footnotetext{
${ }^{23}$ As was shown in Table 1, the duration data include some very long carry drawdown episodes of greater than 300 days. If one eliminated these very long drawdowns, the shape of the hazard function shifts from negative duration dependence to positive for the DM and ALL samples. The EM sample retains the negative slope. Since these long carry episodes are real events in the history, they are included in the sample used to estimate the reported results.
} 
currency carry trade, drawdowns are increasingly less likely to end right after $t$ given that they have lasted until time $t$, as $t$ increases. One can think of this result as an unconditional finding, so that a portfolio manager having no knowledge of determinants of duration would tend to exit carry positions soon after losses are incurred as the expectation is that the drawdown is likely to persist longer, the longer it has lasted.

However, we have seen that this general negative duration dependence result for carry drawdowns is shifted with changes in financial market stress, the carry opportunity set, and deviations from PPP. So knowledge of the value of these factors results in shifts of the hazard function that would help determine the appropriate strategy when faced with a drawdown. If the carry unwind is expected to be brief, then having already sustained a loss, the appropriate strategy may be to hold on to positions in anticipation of the rebound in prices. This would be more likely when the following is true at the start of the drawdown for DM currencies: the lower the financial stress index, the greater the interest differentials, and when value positioning aligns with carry positioning.

\section{Conditioning Carry Exposures}

If a currency fund manager wants to employ an active approach to managing the carry trade, rather than a passive approach, the model presented in the prior section can be used to motivate the construction of a carry portfolio conditioner. The conditioner will reduce risk when the determinants of carry duration indicate that there is a high probability that a carry drawdown will persist for some time into the future. An out-of-sample, implementable conditioner is our first consideration and then we will use the estimated 
hazard function to illustrate how a survivor function approach could be used as an alternative.

Controlling carry risk with determinants of duration. The three determinants of duration, FSI, Carry, and Misvaluation, serve as inputs into conditioning the carry trade exposures. To make each measure comparable over time, we score each variable (convert to standard normal) using a time-varying mean and standard deviation constructed using historical data with an exponentially decaying 3-year half-life. Therefore, at each month, the values of the three inputs are scored using prior historical data on each series so that there is no peeking-ahead and the strategy is fully tradable. Then each variable is allowed to take a weight equal to 1 (full weight), if the z-score is less than or equal to 2 , or 0 (no exposure), if the z-score is greater than 2 . The variables are each given a $1 / 3$ weight in the overall portfolio conditioner, so if only one variable has a $\mathrm{z}$-value greater than 2 , the carry portfolio exposures are reduced by $1 / 3$ but if all have $\mathrm{z}$-scores greater than 2 , the carry portfolio positions would be fully exited. The conditioner is applied in two ways. First, we apply the conditioner to all periods and second, we apply the conditioner only when a carry drawdown is experienced. In this case, we identify the drawdown occurring when a carry loss is greater than $1.5 \%$.

The results in Table 4 indicate that the risk-adjusted returns are favourably impacted by use of the conditioner. Compared to the unconditional case, the Sharpe ratio rises and the tail risk measures of skew and kurtosis are also improved. For instance, using the full DM sample, the Sharpe ratio rises from 0.18 to 0.20 ; the skew falls from - 
0.858 to -0.646 ; and the kurtosis falls from 5.601 to 4.795 . To reiterate, this is a fully implementable strategy as only information available prior to each month is employed in constructing the conditioner. Our results suggest that the determinants of carry drawdown duration can be employed to control risk and improve portfolio performance.

Survivor function conditioner. Duration models may also be analysed in terms of "survivor functions" which measure the probability that an event lasts until a time in the future. In our case, this is the probability that the carry trade drawdown survives until time $t .^{24}$ Evaluating the model estimates at the mean values of the explanatory variables yields a survivor function with values of 0.85 for 5 days, 0.43 for 30 days, and 0.09 for 100 days. Given the mean values of the FSI, Carry, and Misvaluation variables at the start of a drawdown we would assess a $43 \%$ probability that it lasts at least 30 days.

The portfolio manager's problem, when faced with a carry drawdown, is deciding whether to hold onto positions in hopes that the drawdown will soon reverse and the existing positions will yield positive returns again or cut carry exposures in the belief that the drawdown will persist and it is better to reduce exposure to further losses. While there are alternative arbitrary specifications of a decision rule, suppose we assume that the portfolio manager facing a probability greater than 0.5 of a drawdown lasting at least 30 days will exit the carry positions (and positions are held if the probability is less than or equal to 0.5$)$. In the estimation of the probability evaluated at the mean values of the duration determinants of $43 \%$, the PM would hold on to the carry positions, expecting the

\footnotetext{
${ }^{24}$ Using the earlier hazard function notation, the survivor function is written as $S(t \mid x, \beta, \rho, v)=e^{(t / \rho)^{v} e^{\beta x}}$, where $t$ is the number of days in the future.
} 
drawdown to end soon. In this manner, the survivor function could be employed at the start of each drawdown, to help determine whether to cut or hold carry trade exposures. Unlike the earlier conditioner analysis, we cannot conduct a proper out-of-sample backtest using the estimated survivor function due to the limited number of carry drawdown events. We offer this discussion as an example of how it could be employed going forward as the sample size increases.

\section{Conclusion}

There is a long-run positive excess return to currency carry trade portfolios, but there are periodic severe negative return episodes. Digging deeply into carry returns, we chronicle the top-10 drawdowns for each portfolio. Unsurprisingly, the largest DM drawdown is associated with the financial crisis of 2007-2009. However, the longest duration drawdown for the DM portfolio occurs from 1992 to 1995, and is associated with the European exchange rate mechanism crisis. For the EM portfolio, the longest duration drawdown follows the financial crisis, occurring over the 2011-2013 period. Certain currencies appear frequently as major contributors to drawdowns. From the DM list are Australian and New Zealand dollars, Japanese yen, and Swiss franc. From the EM list are Indonesian rupiah, South African rand, Turkish lira, and Brazilian real. The general result that high-interest rate currencies are sold while low-interest rate currencies are bought does not always apply. This is particularly true in the case of EM currencies. In some episodes, the low interest rate EM currencies that are used as short funding currencies are seen to depreciate against the US dollar as EM currencies are sold across 
the board in periods of financial market stress. In these cases, the short side of the carry trade works to mitigate the size of the carry drawdown.

An important dimension of carry drawdowns that has not received attention in the literature, but is of key importance to investors is the duration of drawdowns. We find that drawdowns are increasingly less likely to end tomorrow, given that they have lasted until today, the longer the drawdown has persisted. However, the duration of carry drawdowns varies systematically with a set of variables hypothesized to be important drivers of duration: financial stress (FSI), the carry opportunity set (CARRY), and fundamental value positioning captured by purchasing power parity (PPP). We examine the three duration determinants as conditioning variables used in reducing risk when they signal longer durations of drawdowns. A fully-implementable strategy is created that reduces the carry trade exposures when the determinants signal longer duration of loss. The conditioners improve the risk-adjusted returns and measures of tail risk. We also outline how one can use the conditioning variables to construct estimates of the probability of a drawdown surviving a certain number of days. A portfolio manager could then use the estimated probabilities to inform the decision of how long a carry drawdown is likely to last and whether to reduce carry exposures or not. 


\section{Bibliography}

Daniel, Kent, Robert J. Hodrick, and Zhongjin Lu. 2014. "The carry trade: risks and drawdowns.” NBER Working Paper 20433.

International Monetary Fund, 2008. "Financial stress and economic downturns." World Economic Report: Chapter 4, 129-158.

Jorda, Oscar, and Alan Taylor. 2012. "The carry trade and fundamentals: nothing to fear but FEER itself." Journal of International Economics. vol. 88, no. 1 (September): 74-90.

Jurek, Jakub W., 2014. "Crash-neutral currency carry trades.” Journal of Financial Economics. vol. 113, no. 3 (September): 325-347.

Khandani, Amir E., and Andrew W. Lo. 2011. "What Happened to the Quants in August 2007? Evidence from factors and transactions data." Journal of Financial Markets. Vol. 14, no. 1 (February): 1-46.

Lustig, Hanno., Nikolai Roussanov, and Adrien Verdelhan, 2011. "Common risk factors in currency markets." Review of Financial Studies. vol. 24, no. 11 (November): (37313777. 
Melvin, Michael. and Duncan Shand, 2011. "Active currency investing and performance benchmarks." Journal of Portfolio Management. vol 37, no. 2 (Winter): 46-59.

Melvin, M. and Taylor, M., 2009. The crisis in the foreign exchange market. Journal of International Money and Finance. vol. 28, no. 8 (December) 1317-1330.

Pedersen, Lasse H., 2009. "When everyone runs for the exit." NBER Working Paper No. w15297.

Pojarliev, M. and Levich, R., 2008. "Do professional currency managers beat the benchmark?" Financial Analysts Journal. vol. 64, no. 5 (September/October): 18-32.

_ 2011. "Detecting Crowded Trades in Currency Funds." Financial Analysts

Journal, vol. 67, no. 1 (January/February): 26-39. 
Table 1: The Top 10 Drawdowns from Currency Carry Trade Portfolios

1.a. Developed Market Currencies

\begin{tabular}{lllll}
\hline Order & Start Date & End Date & Length & $\begin{array}{l}\text { Percentage } \\
\text { Drawdown }\end{array}$ \\
\hline 1 & 24-Jul-07 & 2-Feb-09 & 399 & $31.99 \%$ \\
2 & 8-Sep-92 & 19-Apr-95 & 689 & $27.37 \%$ \\
3 & 7-Apr-86 & 10-Sep-86 & 114 & $19.72 \%$ \\
4 & 11-Apr-13 & 27-Aug-13 & 98 & $11.08 \%$ \\
5 & 8-Oct-87 & 31-Dec-87 & 61 & $9.96 \%$ \\
6 & 5-Dec-05 & 22-May-06 & 120 & $9.87 \%$ \\
7 & 4-Aug-98 & 19-Oct-98 & 54 & $8.74 \%$ \\
8 & 23-Aug-90 & 18-Oct-90 & 41 & $7.59 \%$ \\
9 & 18-Feb-04 & 18-May-04 & 64 & $7.53 \%$ \\
10 & 12-Jun-02 & 24-Jul-02 & 30 & $7.15 \%$
\end{tabular}

1.b. Emerging Market Currencies

\begin{tabular}{lllll}
\hline Order & Start Date & End Date & Length & $\begin{array}{l}\text { Percentage } \\
\text { Drawdown }\end{array}$ \\
\hline 1 & 11-Feb-98 & 17-Jun-98 & 92 & $16.90 \%$ \\
2 & 2-Sep-08 & 22-Oct-08 & 36 & $16.38 \%$ \\
3 & 21-Feb-01 & 23-Feb-01 & 2 & $15.43 \%$ \\
4 & 8-Apr-11 & 28-Aug-13 & 623 & $15.20 \%$ \\
5 & 19-Apr-06 & 25-May-06 & 26 & $9.51 \%$ \\
6 & 14-Jan-08 & 31-Mar-08 & 55 & $9.13 \%$ \\
7 & 23-Jul-07 & 16-Aug-07 & 18 & $8.19 \%$ \\
8 & 27-May-02 & 16-Jul-02 & 36 & $6.36 \%$ \\
9 & 21-Oct-98 & 4-Nov-98 & 11 & $6.05 \%$ \\
10 & 15-Oct-09 & 22-Dec-09 & 48 & $5.26 \%$
\end{tabular}


1.c. All Currencies

\begin{tabular}{lllll}
\hline Order & Start Date & End Date & Length & $\begin{array}{l}\text { Percentage } \\
\text { Drawdown }\end{array}$ \\
\hline 1 & 4-Aug-08 & 2-Feb-09 & 130 & $23.08 \%$ \\
2 & 25-Aug-92 & 19-Apr-95 & 699 & $22.83 \%$ \\
3 & 1-May-98 & 17-Jun-98 & 34 & $16.05 \%$ \\
4 & 31-May-86 & 22-Aug-86 & 60 & $14.58 \%$ \\
5 & 8-Apr-11 & 28-Aug-13 & 623 & $14.30 \%$ \\
6 & 21-Feb-01 & 23-Feb-01 & 2 & $13.56 \%$ \\
7 & 6-Aug-97 & 28-Oct-97 & 60 & $11.24 \%$ \\
8 & 31-Oct-07 & 31-Mar-08 & 108 & $10.77 \%$ \\
9 & 21-Apr-06 & 24-May-06 & 23 & $9.32 \%$ \\
10 & 23-Jul-07 & 16-Aug-07 & 18 & $8.96 \%$
\end{tabular}

Note: The carry portfolios are implemented as long positions in the top 3 interest rate currencies funded by short positions in the lowest 3 interest rate currencies, all equally weighted. 
Table 2: Individual Currency Attribution during Top Carry Drawdowns

\section{2.a. Developed Market Currencies}

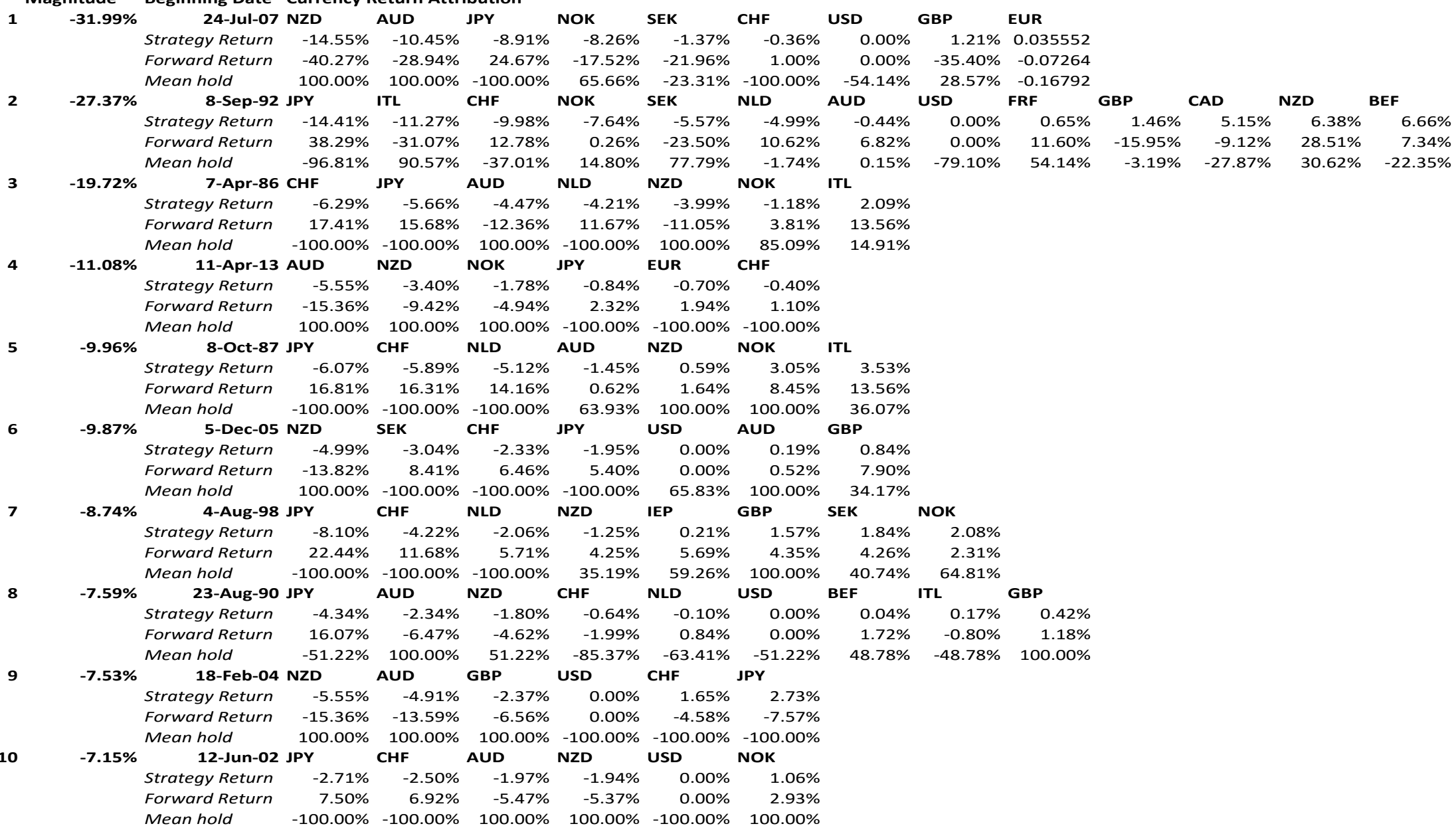




\section{2.b. Emerging Market Currencies}

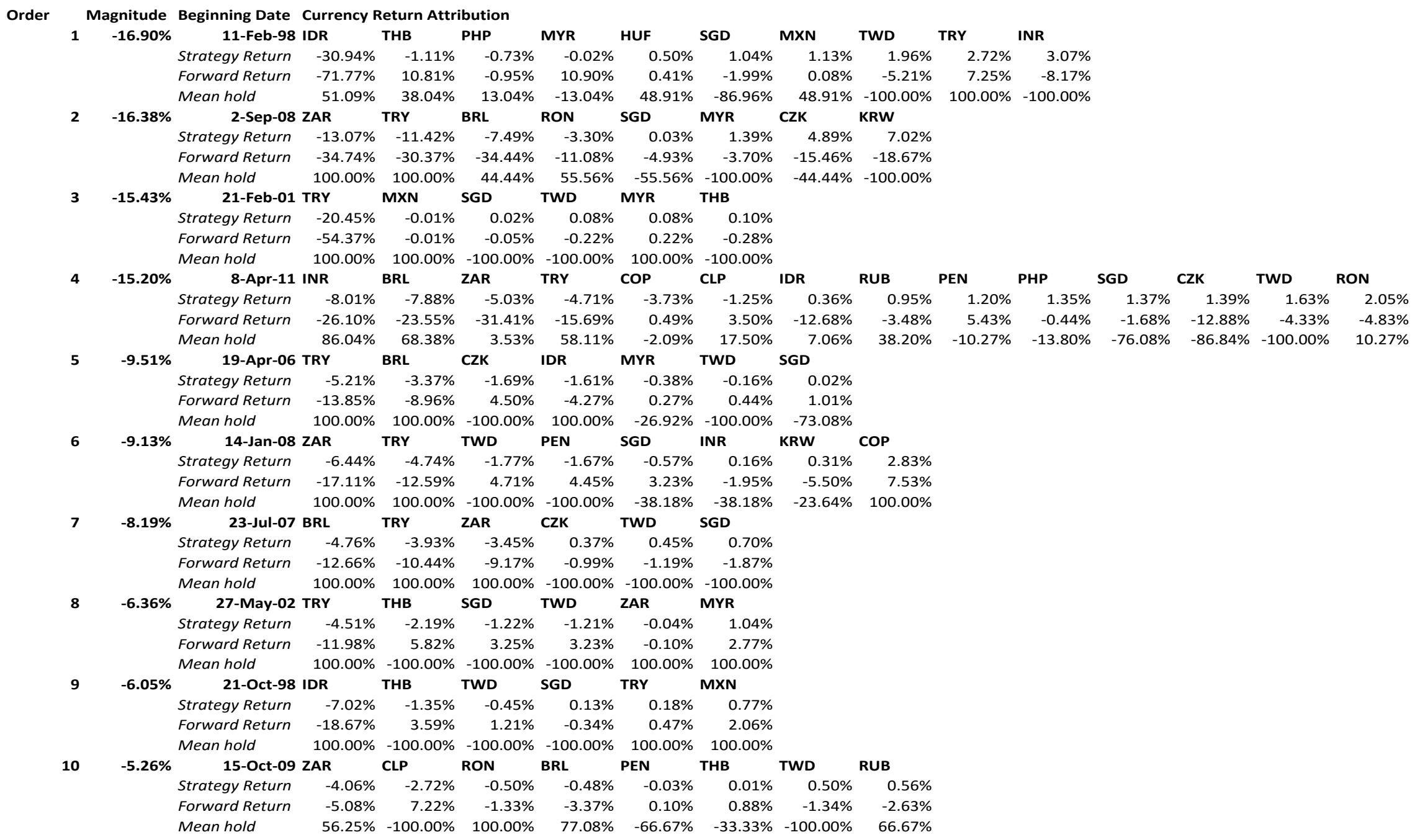




\section{2.c. All Currencies}

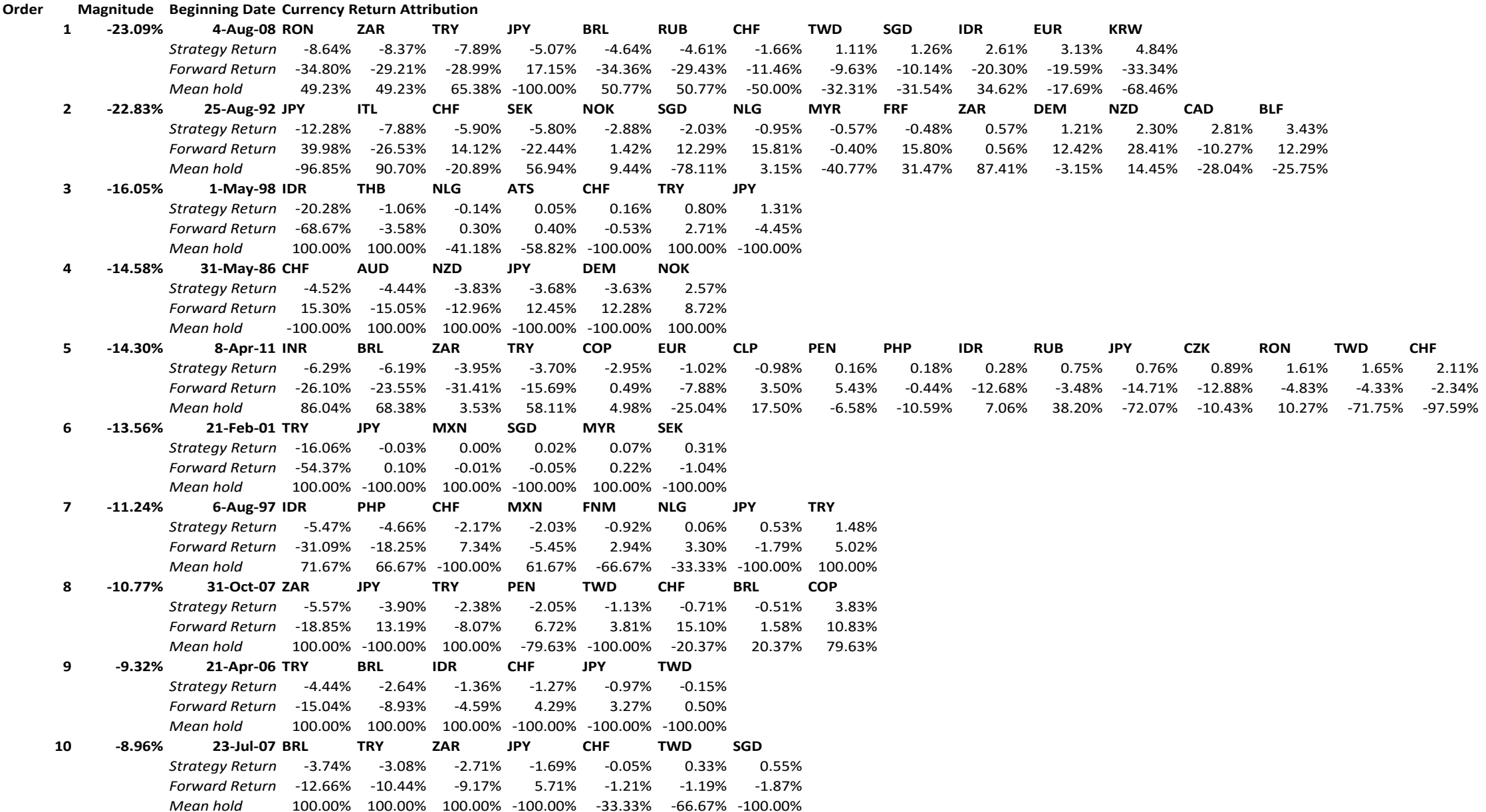

Notes: We focus on the following set of currencies that are widely traded by active currency investors (ISO codes in parentheses): Australia (AUD), Brazil (BRL), Canada (CAD), Chile (CLP), Colombia (COP), Czech Republic (CZK), Euro (EUR), Hungary 
(HUF), India (INR), Indonesia (IDR), Japan (JPY), Malaysia (MYR), Mexico (MXN), New Zealand (NZD), Norway (NOK), Peru (PEN), Philippines (PHP), Poland (PLN), Romania (RON), Russia (RUB), Singapore (SGD), South Africa (ZAR), South Korea (KRW), Sweden (SEK), Switzerland (CHF), Taiwan (TWD), Thailand (THB), Turkey (TRY), and the United Kingdom (GBP). In addition, prior to the euro, the legacy currencies that appear in the portfolios include Belgium (BEF), Finland (FNM), France (FRF), Germany (DEM), Ireland (IRP), Italy (ITL), and Netherlands (NLG). The table lists the magnitude of the loss, the date the event started, and for each currency in the carry portfolio, its gain or loss in the portfolio, its realized return (Forward Return), and the mean size of the position in the portfolio over the event (Mean Hold). 
Table 3: Duration Model of Carry Drawdowns

\begin{tabular}{lll}
\hline $\begin{array}{l}\text { Dependent Variable: } \\
\text { Variable }\end{array}$ & $\begin{array}{ll}\text { Doefficient } \\
\text { Co- } \\
\text { value }\end{array}$ \\
\hline FSI & -0.033 & 0.01 \\
Carry & 4.008 & 0.00 \\
Misvaluation & -2.104 & 0.00 \\
& & \\
$\rho$ & 69.90 & \\
$v$ & 0.85 & \\
Log L & 4.645 & \\
& & \\
\hline
\end{tabular}

\begin{tabular}{lll}
\hline $\begin{array}{l}\text { Dependent Variable: EMduration } \\
\text { Variable }\end{array}$ & $\begin{array}{l}\text { Coefficient } \\
P \text { - } \\
\text { value }\end{array}$ \\
\hline FSI & 0.150 & 0.00 \\
Carry & -0.364 & 0.08 \\
Misvaluation & -2.856 & 0.00 \\
& & \\
$\rho$ & 63.9 & \\
$v$ & 0.77 & \\
Log L & 4.036 &
\end{tabular}

\begin{tabular}{lll}
\hline $\begin{array}{l}\text { Dependent Variable: } \\
\text { ALLduration } \\
\text { Variable }\end{array}$ & & \\
& $\begin{array}{l}\text { Coefficien } \\
t\end{array}$ & $\begin{array}{l}P \text { - } \\
\text { value }\end{array}$ \\
\hline FSI & -0.354 & 0.00 \\
Carry & 1.993 & 0.00 \\
Misvaluation & -0.610 & 0.00 \\
& & \\
$\rho$ & 67.38 & \\
$v$ & 0.76 & \\
Log L & 4.487 &
\end{tabular}


Table 4: Conditioning Carry Exposures with Determinants of Duration

\begin{tabular}{|c|c|c|c|c|c|c|c|c|c|}
\hline & & DM & & & EM & & & ALL & \\
\hline & $\underline{\text { Unconditional }}$ & $\underline{\text { All data }}$ & loss $>1.5 \%$ & Unconditional & $\underline{\text { All data }}$ & loss $>1.5 \%$ & $\underline{\text { Unconditional }}$ & All data & Ipss $>1.5 \%$ \\
\hline Return & 0.005 & 0.005 & 0.005 & 0.012 & 0.012 & 0.012 & 0.007 & 0.007 & 0.007 \\
\hline Risk & 0.026 & 0.025 & 0.025 & 0.027 & 0.026 & 0.027 & 0.026 & 0.025 & 0.025 \\
\hline Sharpe ratio & 0.180 & 0.200 & 0.197 & 0.431 & 0.446 & 0.440 & 0.289 & 0.300 & 0.299 \\
\hline skew & -0.858 & -0.646 & -0.651 & -0.558 & -0.583 & -0.503 & -0.542 & -0.507 & -0.478 \\
\hline kurtosis & 5.601 & 4.795 & 4.775 & 4.952 & 4.937 & 4.884 & 4.601 & 4.331 & 4.274 \\
\hline
\end{tabular}


Figure 1: Cumulative Performance of the Carry Trade for All Currencies

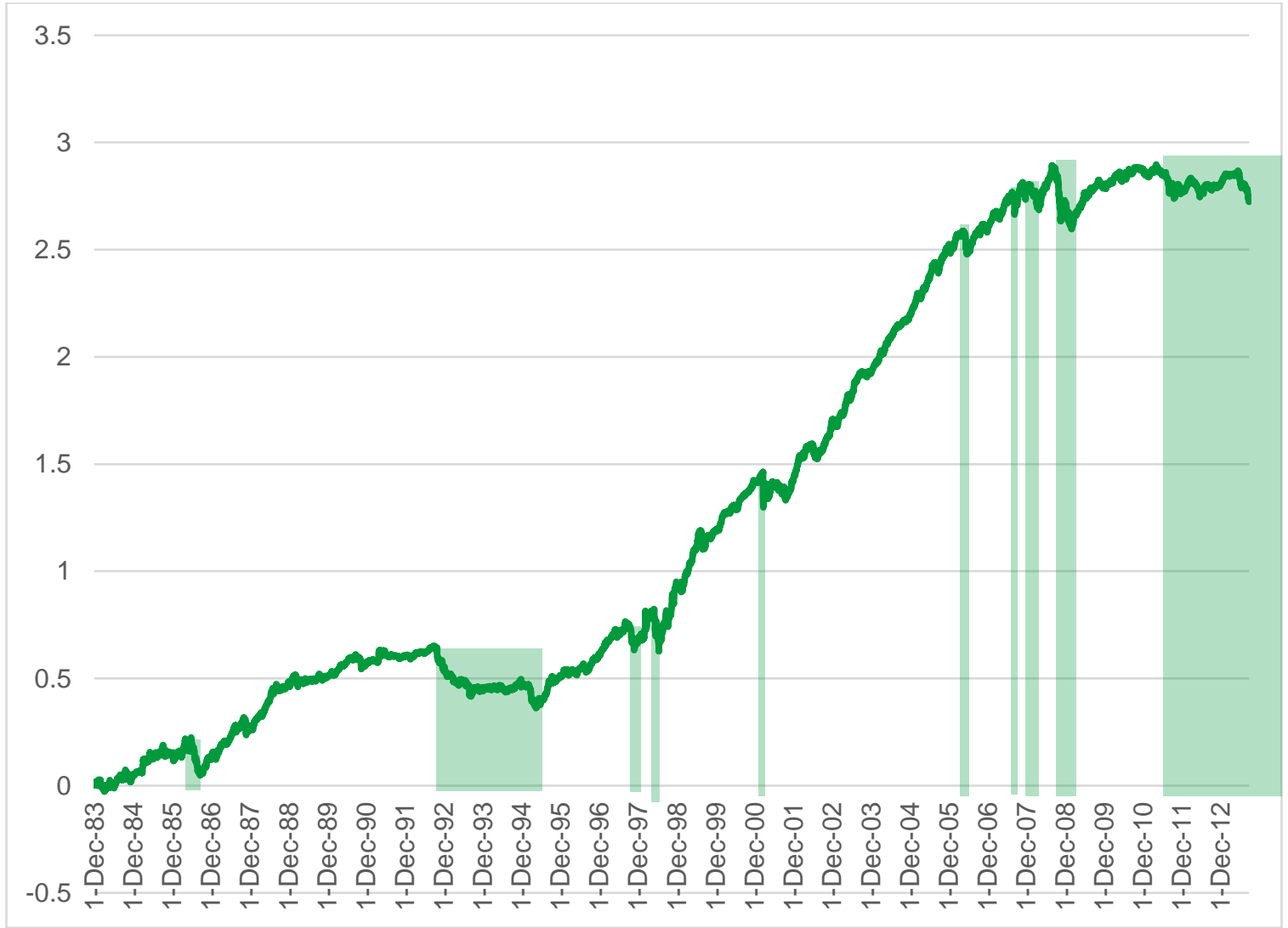

Shaded areas represent the top-10 drawdown periods. 
Figure 2: Cumulative Performance of the Carry Trade for Portfolios of Developed and Emerging Market Currencies

2.a. Developed market returns

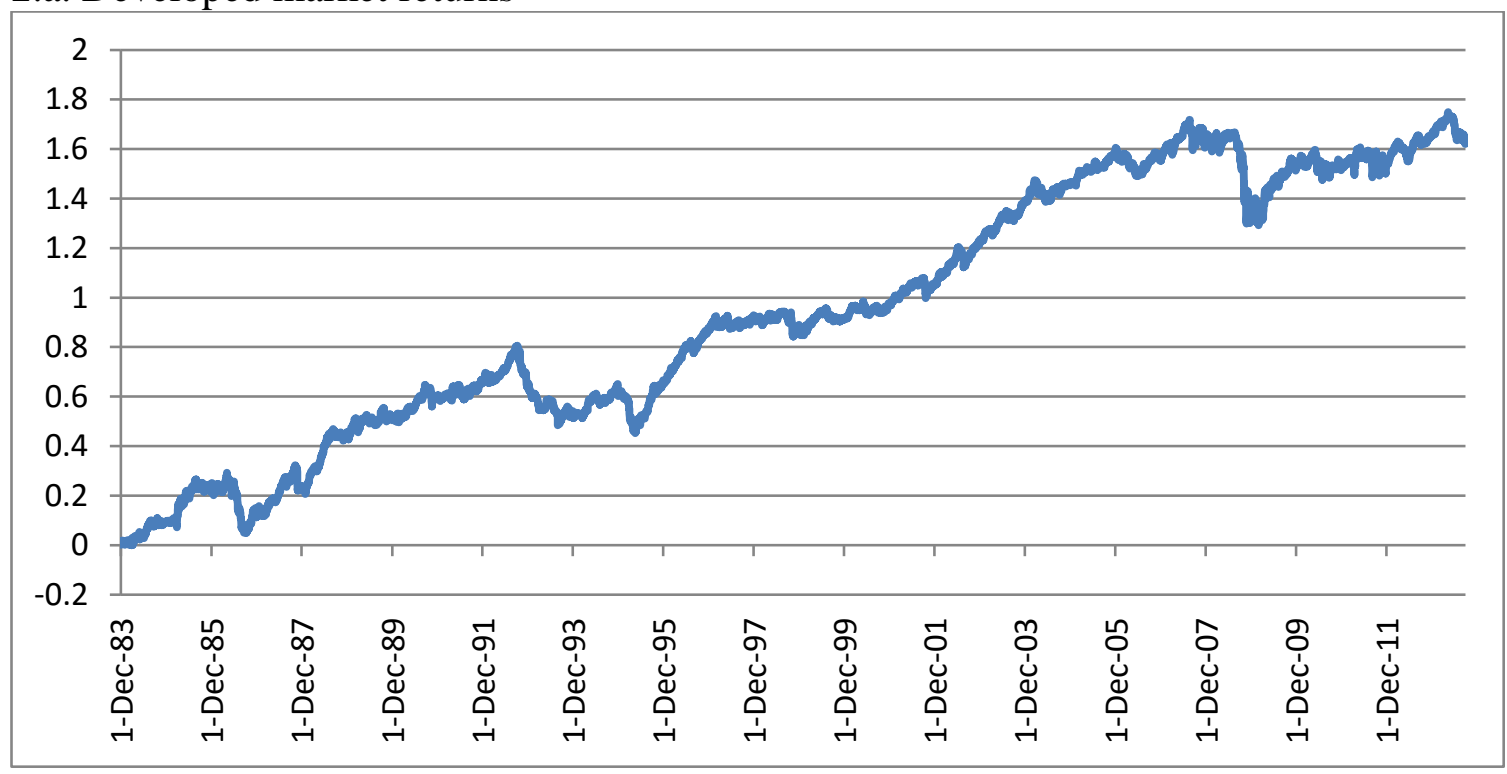

2.b. Emerging market returns

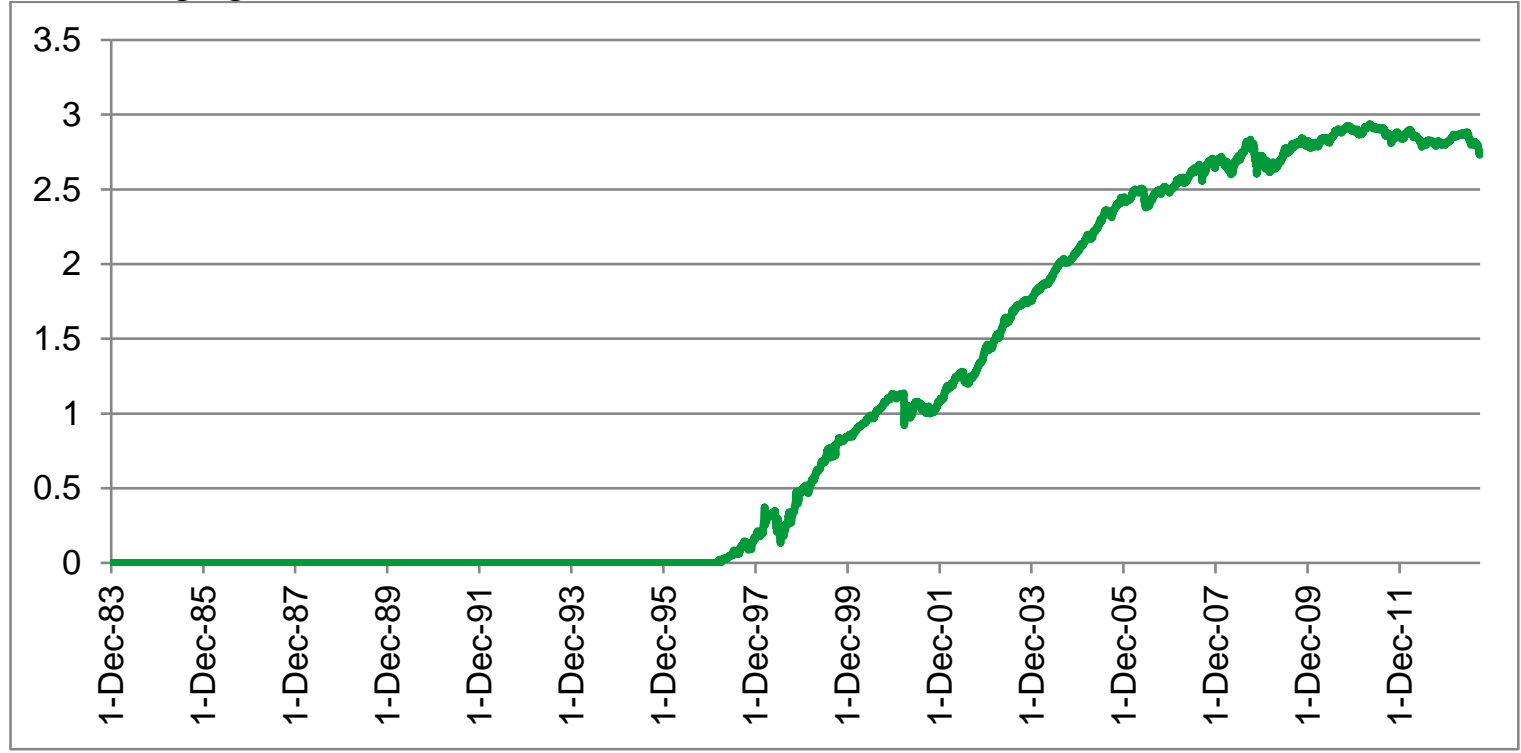




\section{Figure 3: Summary Statistics for Daily Currency Carry Returns}

Figure 3a: Developed Market Returns

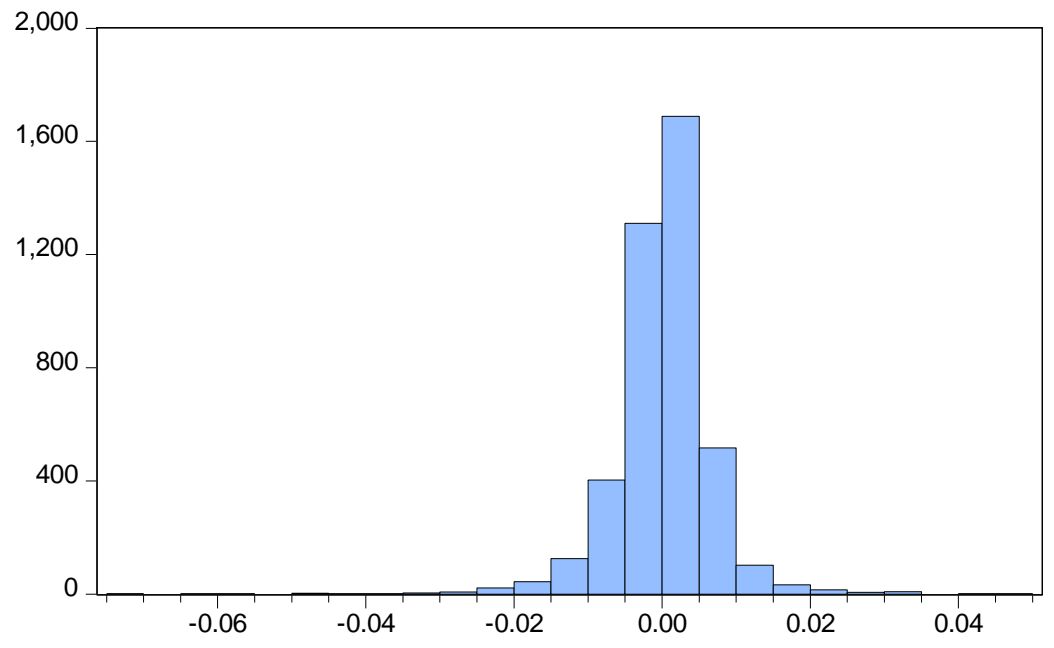

Series: RETURNDM

Sample 2/03/1997 8/30/2013

Observations 4293

Mean $\quad 0.000195$

Median $\quad 0.000477$

Maximum 0.047046

Minimum $\quad-0.071169$

Std. Dev. $\quad 0.006627$

Skewness $\quad-0.947274$

Kurtosis $\quad 15.06914$

Jarque-Bera 26697.72

Probability $\quad 0.000000$

Figure 3b: Emerging Market Returns

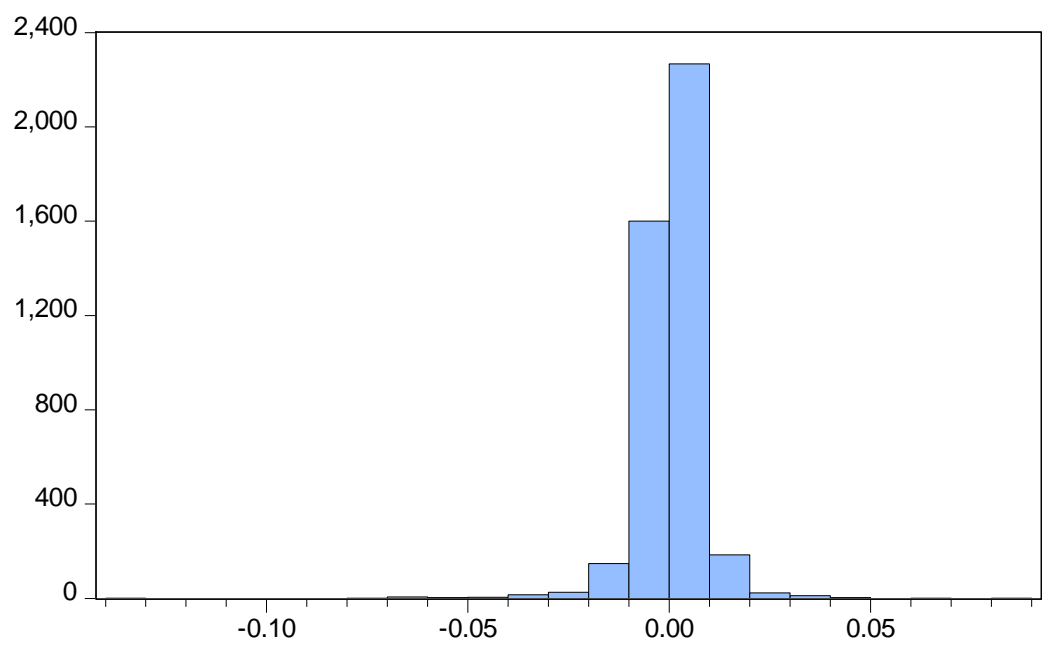

Series: RETURNEM

Sample 2/03/1997 8/30/2013

Observations 4293

Mean $\quad 0.000566$

Median $\quad 0.000844$

Maximum $\quad 0.083568$

Minimum $\quad-0.135749$

Std. Dev. $\quad 0.007996$

Skewness $\quad-2.150936$

Kurtosis $\quad 38.71476$

Jarque-Bera 231473.2

Probability $\quad 0.000000$ 
Figure 3c: DM and EM Combined Returns

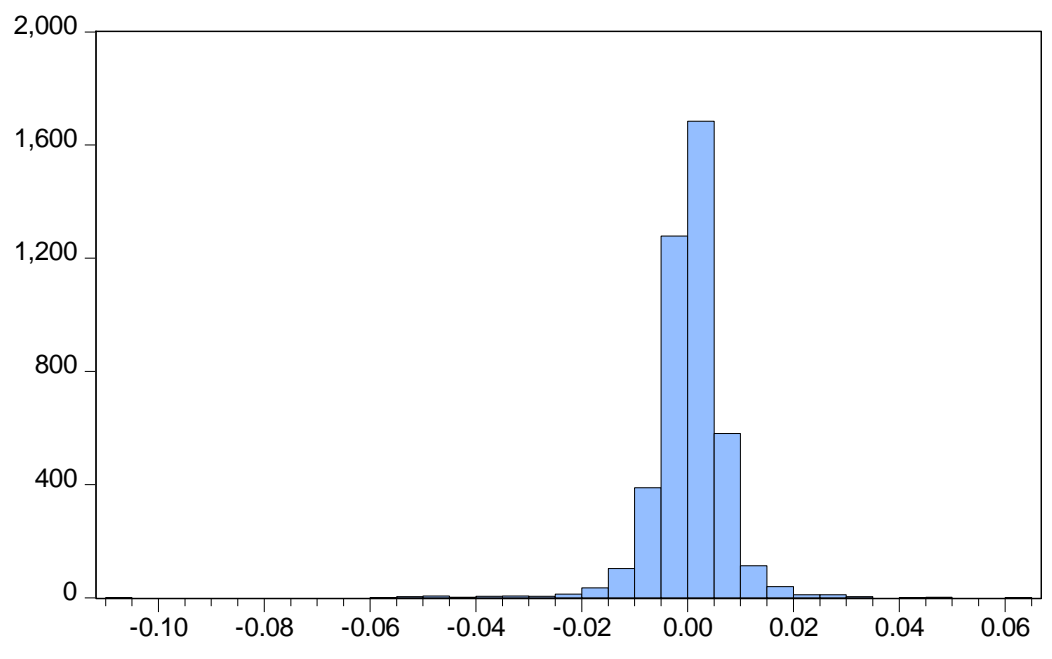

\begin{tabular}{|lc|}
\hline Series: RETURNALL \\
Sample 2/03/1997 8/30/2013 \\
Observations & 4293 \\
& \\
Mean & 0.000456 \\
Median & 0.000698 \\
Maximum & 0.064575 \\
Minimum & -0.106957 \\
Std. Dev. & 0.007056 \\
Skewness & -1.698954 \\
Kurtosis & 27.31297 \\
& \\
Jarque-Bera & 107801.9 \\
Probability & 0.000000
\end{tabular}


Figure 4: Global Financial Stress Index (FSI) and its Components

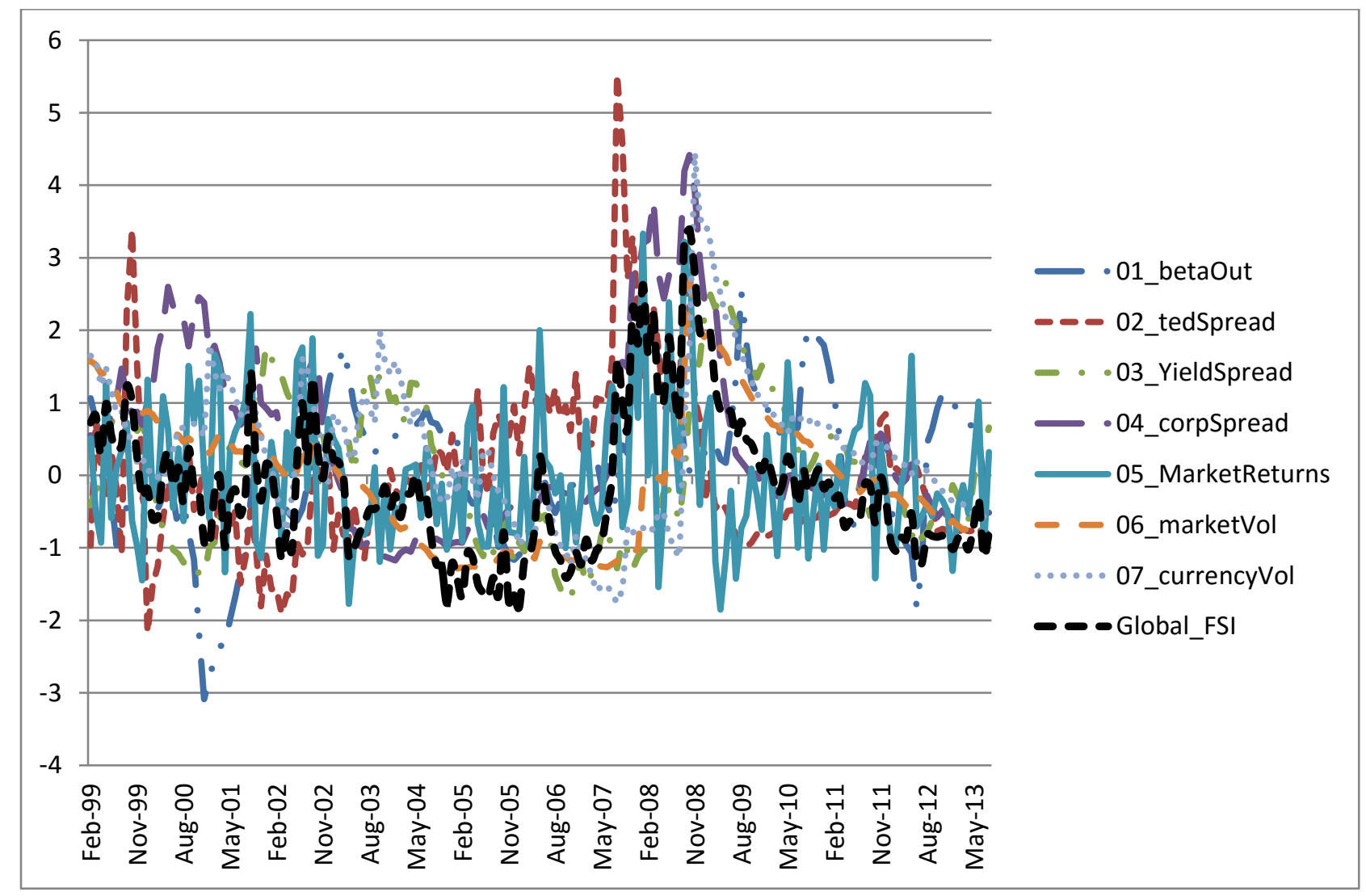


Figure 5: Hazard Functions Estimated for DM, EM, and ALL Duration Models
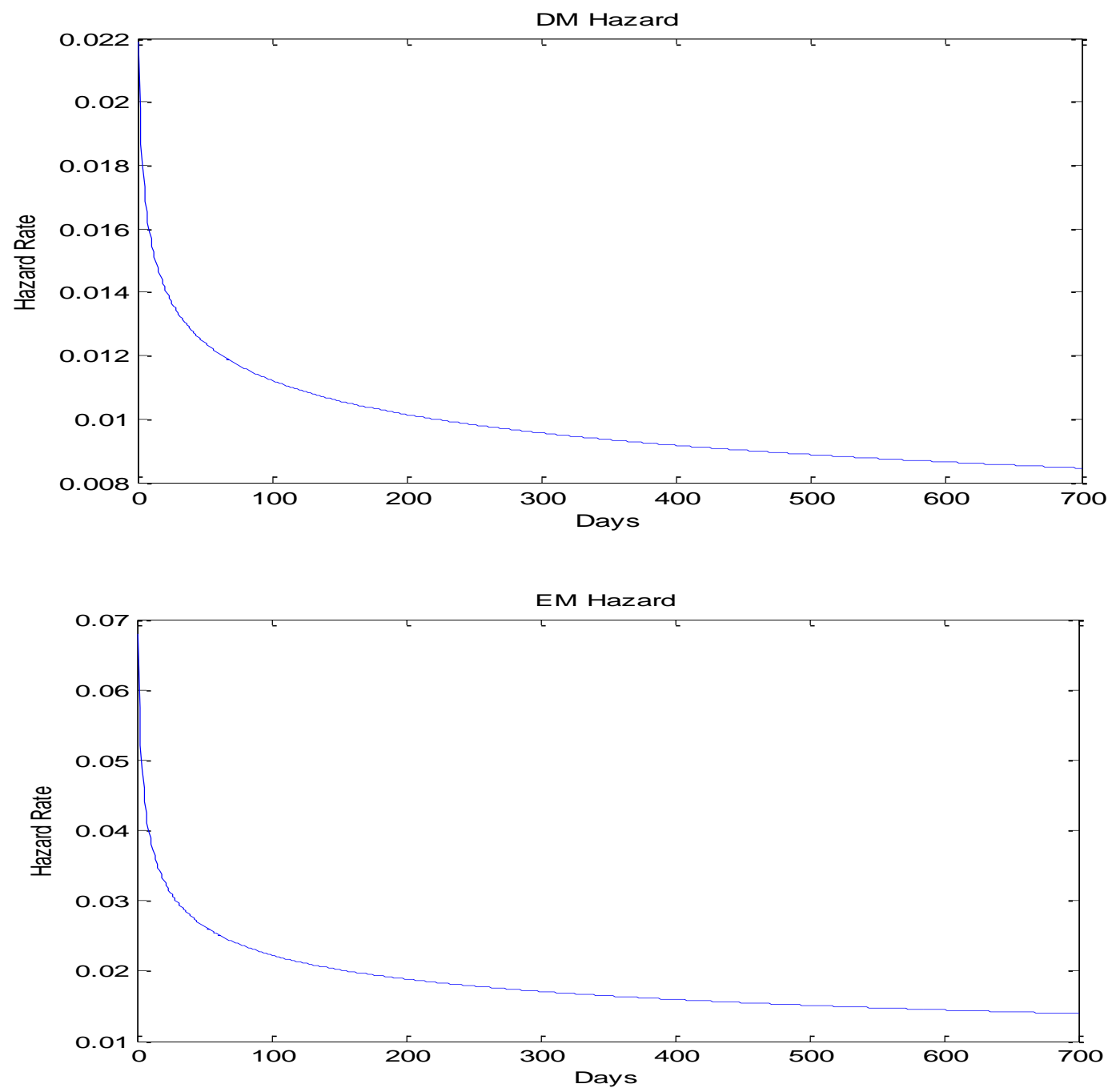


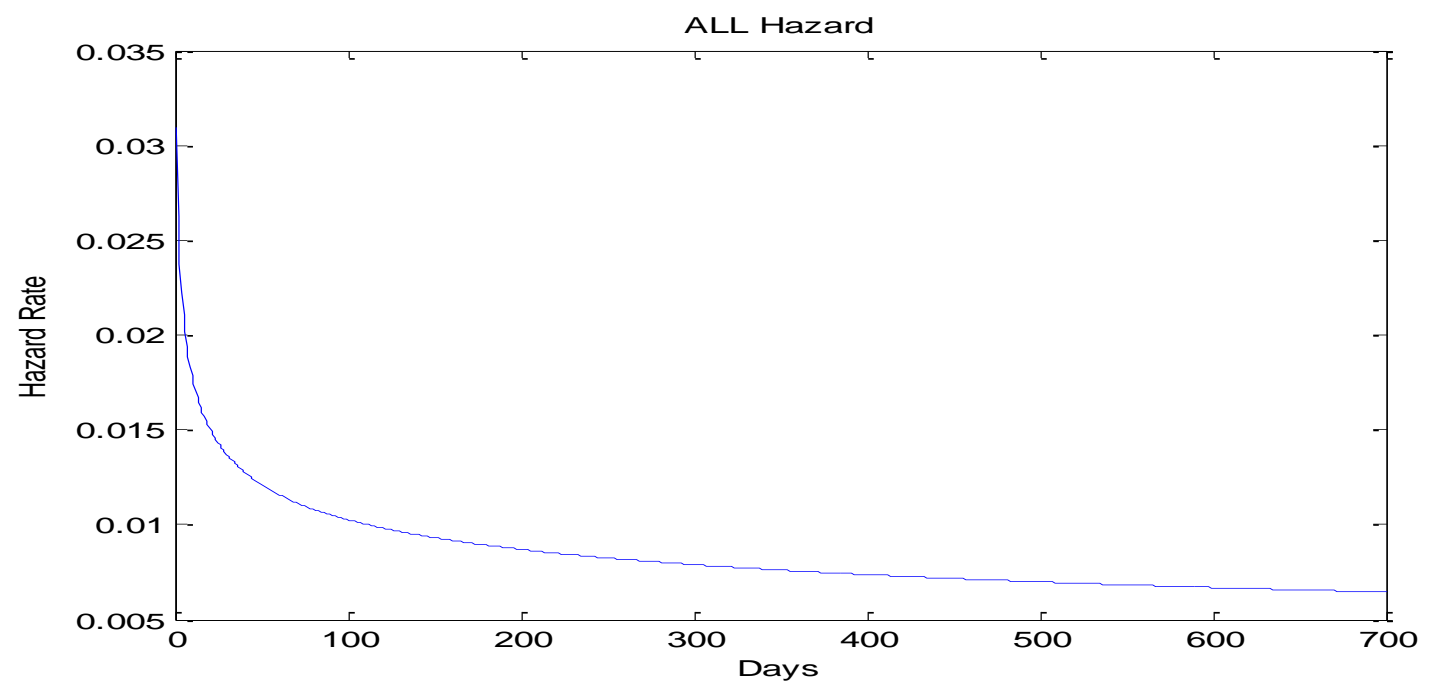




\section{Appendix: Narrative Description of Events Associated with Top 10 Drawdowns}

Drawing on press reports at the time of each event, a description of major contributing factors is presented. The text is cryptic as one finds on Bloomberg.

\section{Developed Market Currencies}

1. 7/24/07 to 2/2/09: The onset of the subprime and credit crisis. "Emerging credit concerns in global credit markets" preceded a sell-off in the carry trade. In August, the quant equity unwind occurred.

2. 9/8/92 to 4/19/95: ERM crisis. On September 141992 the Italian Lira devalued 7\%. September 161992 Italian Lira and Sterling leave ERM, Spanish Peseta devalued 5\%. For full ERM crisis timeline see: http://reszatonline.wordpress.com/2011/08/19/note-the-parallelstimeline-ems-crisis-2/. This period also included the Mexican peso crisis of December 1994. 3. 4/7/86 to 9/10/86: The realignment of the European Monetary System meant devaluation of some European currencies immediately and interest rate cuts in, for example, Belgium. In the immediate aftermath, a number of the devalued currencies traded in the upper half of their permitted ranges, so the immediate drop in their values was much less than the official devaluation.

4. 4/11/13 to 8/27/13: Wave of central bank cuts (including RBA and EM currencies). This was followed by more concerted reduction of carry trades in May on discussion around US Fed tapering.

5. 10/8/87 to 12/31/87: After two years of continued intervention, major central banks stepped away from intervening to stop dollar depreciation. Massive intervention earlier this year to prop 
up the dollar, to the tune of 70 to 90 billion dollars, has boosted money supply growth in Japan and West Germany, rekindling inflationary pressures. On October 19, the "Black Monday" stock market crash occurred with the Dow Jones index falling $22 \%$.

6. $12 / 5 / 05$ to 5/22/06: Monetary policy and oral intervention on the NZD. "Not only did the statement signal softer interest rates, but it also mentioned the strength of the currency as an explicit risk to the outlook," said John McDermott, Chief Economist at ANZ Bank. McDermott was referring to Gov Bollard's comments that the Kiwi was at unjustifiable levels.

7. 8/4/98 to 10/19/98: The initial drop was associated with a steep sell-off in US stocks, which resulted in risk reduction across portfolios. Then on 17 August 1998 Russia defaulted on its debt. This sparked outflows to safe haven currencies such as JPY and CHF.

8. 8/23/90 to 10/18/90: There were heightened Middle East geopolitical tensions followed by the US invasion of Kuwait.

9. 2/18/04 to 5/18/04: Concerted Bank of Japan intervention. Japan has intervened on six days since May 22 in an attempt to curb the export-harming strength of the yen, but has failed to stop its relentless rise to nine-month highs beyond the psychologically key 120 per dollar. The yen has risen 10 yen or around eight percent against the dollar since early May. Analysts said that as the yen has risen, investors who had borrowed, or gone short of yen, to invest in higher-yielding markets, were forced to buy back the Japanese currency. This had contributed to a drop in the value of the Australian and New Zealand dollars against the yen, added to pressure on the dollar/yen exchange rate, and could also affect other currencies such as South Africa's rand and sterling. "We have seen a huge correction lower this week in the Australian and New Zealand dollars against the yen," said Rob Hayward, senior foreign exchange strategist at ABN Amro."There has been selling from Japanese sources as some people have been squeezed on the 
yen side. The Australian dollar hit three-month lows against the yen on Friday, a drop of seven percent from 2-1/2 year highs set only a few weeks ago The New Zealand dollar has also fallen by seven percent against the yen in the past few weeks, and the Canadian dollar has lost 3.5 percent.

10. $6 / 12 / 02$ to $7 / 24 / 02$ : At the start of the period, there were moderate losses for the carry trade which were contemporaneous with heightened geopolitical tensions in middle-east between Israel and Palestine. At the end of the period there were larger declines contemporaneous with large losses in the US equity market. The WorldCom bankruptcy was announced on July 19, the largest bankruptcy ever.

\section{Emerging Market Currencies}

1. 2/11/98 to 6/17/98: Almost entirely an Indonesian event occurring in the height of the Indonesian wave of the Asian financial crisis. Indonesia had talked of pegging to the US Dollar, this did not happen. In Feb 1998 President Suharto fired Bank of Indonesia Governor Soedradjad. Following the IMF conditionality program and associated austerity, there was widespread rioting and social unrest.

2. 9/2/08 to 10/22/08: In the run-up to the global financial crisis, liquidity in EM currencies fell drastically leading to a cross EM currency sell off, high-beta and carry currencies were worst affected. On September 15, Lehman Bros filed for bankruptcy.

3. 2/21/01 to 2/23/01: Almost entirely a Turkish event associated with the collapse of the stock market and the financial crisis that saw panic selling of Turkish assets. This resulted in the abandonment of the exchange rate peg that was an anchor of the inflation control program. 
4. $4 / 8 / 11$ to $8 / 28 / 13$ : This was a very long carry unwind episode, the period is characterized by relatively poor economic data from emerging market countries but no big sell off. Recoveries were seen, but not so as to reach a new peak of performance before the Bernanke QE tapering speech in May 2013. The drawdown prior to May 2013 would not have been in the top 10 (max drawdown of 4.8\%). The largest part of the drawdown happened post Fed tapering discussions. The start of the drawdown appears to be associated with a risk-off sentiment shift caused by an IMF downgrade of the growth outlook for Japan and the US. This period also included the S\&P downgrade of U.S. government debt from AAA on August 5, 2011; the Cypriot financial crisis when the government requested a bailout from the EFSF; and the Italian election of February 2013 which failed to form a stable government.

5. 4/19/06 to 5/25/06: Emerging market sell off precipitated by Turkish macroeconomic news, in particular, inflation print at 3 times expectation and large current account deficit.

6. 1/14/08 to 3/31/08: Largely a South Africa and Turkey event. The ZAR depreciated by $9 \%$ in Jan 2008 as the market expected a central bank rate hike that did not occur. This, coupled with weakening economic data and political unrest, all hit the rand in early 2008. Concerns over slowing growth and political conflict between religious and secular interests led to a sell-off of TRY. This period also included the Bear Stearns bailout on March 14.

7. 7/23/07 to 8/16/07: This was started by more bad news about US housing and further information feeding into the subprime and credit crisis. The de-risking impacted emerging markets as well as developed markets. See 1 of DM.

8. 5/27/02 to 7/16/02: Turkish politics associated with start of event. The Turkish government undertook a number of reforms aimed at stabilizing the Turkish economy in preparation for accession negotiations with the European Union. However, the short-term economic pain 
brought on by the reforms caused rifts within the governing coalition. The TRY depreciated from about 1.42 to 1.68 per USD over the period.

9. 10/21/98 to 11/4/98: Largely an Indonesian event, as the country was recovering from the Asian crisis, the Rupiah appreciated rapidly from June 2008 (16,000 IDR per USD) to October (approached 7000 per USD). Then there was intervention, due to worries about the strength of the currency affecting exports and economic growth, resulting in a sharp depreciation back towards 7700 on Oct 21 , which continued until reaching 8750 by Nov 4 , after which it stabilized. 10. 10/15/09 to 12/22/09: In the aftermath of Lehman, there were considerable concerns about credit risk and a global growth slowdown. The associated deleveraging resulted in a sell-off of risk positions which hit EM over this period. 